\title{
User Design Research: An Investigation into Interprofessional Rehabilitation Care Practices of Geriatric Patients with Hip Surgery
}

by

\author{
Diana Isaza Shelton
}

A thesis submitted to the Faculty of Graduate and Postdoctoral Affairs in partial fulfillment of the requirements for the degree of

\author{
Master of Design \\ in \\ Industrial Design \\ Carleton University \\ Ottawa, Ontario
}

C 2013, Diana Isaza Shelton 
Library and Archives

Canada

Published Heritage

Branch

395 Wellington Street

Ottawa ON K1A ON4

Canada
Bibliothèque et

Archives Canada

Direction du

Patrimoine de l'édition

395 , rue Wellington

Ottawa ON K1A ON4

Canada
Your file Votre référence

ISBN: 978-0-494-94615-2

Our file Notre référence

ISBN: $978-0-494-94615-2$
NOTICE:

The author has granted a nonexclusive license allowing Library and Archives Canada to reproduce, publish, archive, preserve, conserve, communicate to the public by telecommunication or on the Internet, loan, distrbute and sell theses worldwide, for commercial or noncommercial purposes, in microform, paper, electronic and/or any other formats.

The author retains copyright ownership and moral rights in this thesis. Neither the thesis nor substantial extracts from it may be printed or otherwise reproduced without the author's permission.
AVIS:

L'auteur a accordé une licence non exclusive permettant à la Bibliothèque et Archives Canada de reproduire, publier, archiver, sauvegarder, conserver, transmettre au public par télécommunication ou par l'Internet, prêter, distribuer et vendre des thèses partout dans le monde, à des fins commerciales ou autres, sur support microforme, papier, électronique et/ou autres formats.

L'auteur conserve la propriété du droit d'auteur et des droits moraux qui protege cette thèse. $\mathrm{Ni}$ la thèse ni des extraits substantiels de celle-ci ne doivent être imprimés ou autrement reproduits sans son autorisation.
In compliance with the Canadian Privacy Act some supporting forms may have been removed from this thesis.

While these forms may be included in the document page count, their removal does not represent any loss of content from the thesis.
Conformément à la loi canadienne sur la protection de la vie privée, quelques formulaires secondaires ont été enlevés de cette thèse.

Bien que ces formulaires aient inclus dans la pagination, il n'y aura aucun contenu manquant. 


\begin{abstract}
As the healthcare space finds its way towards a more sustainable provision of care and a pleasurable healthcare experience for clinicians and patients, design research opportunities emerge. New collaborative models of care are changing the requirements that information and communication tools must fulfill. New product developers ought to understand these clinical processes and the emerging user requirements in order to develop innovative tools that fit seamlessly into the work practice. In this area of rapid change, design researchers appear to have limited experience.
\end{abstract}

The aim of this thesis is to identify the needs of an interprofessional care team collaborating in geriatric rehabilitation care with a view to uncovering user design insights that can inform the development of health products. This investigation adopts an interdisciplinary approach using Industrial Design and Human Computer Interaction skill sets to deepen the ability of conducting user design research. The descriptive case study provides a rich picture of the care process of post-operative hip surgery patients, which in turn, reveals user design insights. Description of team practices and professionals' views were gathered through semi-structured interviews, artifact analysis of materials used in the practice, and archival data from the institution.

While findings demonstrate a strong collaborative practice with highly interdependent roles and shared decision-making, they also indicate that current artifacts for information sharing and communication do not optimally support the needs of the clinical team and the patient. The study identified the need for: integrated, convenient and easy-to-use recording instruments in assessment; tools for tracking, visualizing and analyzing patient mobility performance; shared care plans and evaluation of discharge options; tools to support patient education and coaching; and reliable $\&$ continuous ways to communicate patient status and coordinate treatment and discharge. A conceptual model represents the areas in which design could prove beneficial.

Keywords: Interprofessional care, healthcare, user-centered design, user design research, needs analysis 


\section{ACKNOWLEDGMENTS}

To God, for giving me this challenge and the opportunity to grow.

To my husband Paul, for being so silently patient and undoubtedly supportive from beginning to end.

To my son Nicolas, for being... your existence has made this journey the reason for not giving up... never give up son!... It is as much about the journey, as it is about the destination.

To my two supervisors Lois Frankel and Gitte Lindgaard, for standing right beside me... walking me in the messiness of my thoughts, through what at times felt impossible, being so patient and compassionate. Thank you for not letting me give up.

To my beloved family who in the distance always kept me in their prayers, cheering me up and trusting in me.

To my dear friends Kathleen, Angela and Susana, who kept me from going insane, lifted me up in the toughest moments and reminded me to believe in myself.

To all those around me who, through their experiences, opinions, revisions, and ideas contributed in the construction of my own.

To my feline and canine companions, Cleo and Luna, whose unconditional love was a constant reminder of the present.

To all those who believed in me... and also those who did not ... Thank you! because you gave me another reason to get it done... here it is! 


\section{TABLE OF CONTENTS}

ABSTRACT

ACKNOWLEDGMENTS................................................................................................................................................................. iii





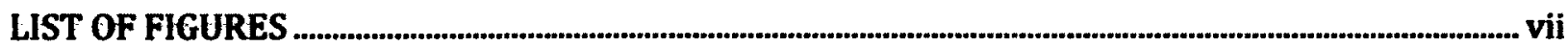

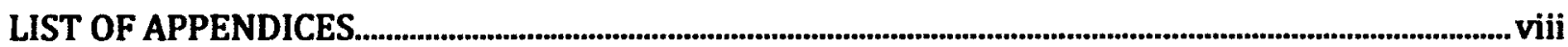

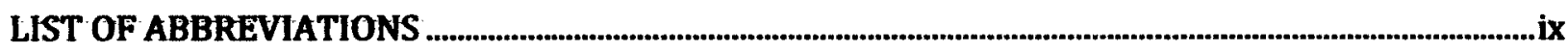

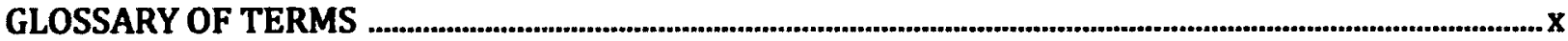

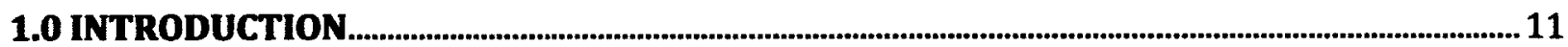

1.1 Background .............................................................................................................................................. 12

1.2 Statement of the problem .............................................................................................................................. 13

1.3 Focus of the study ................................................................................................................................... 14

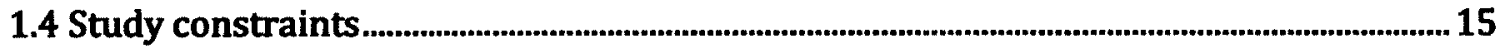

1.5 Significance of the study........................................................................................................................... 15

1.6 Research questions......................................................................................................................................... 16

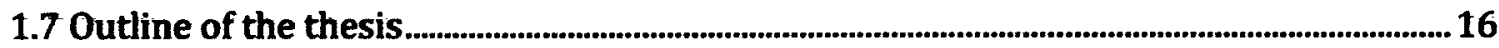

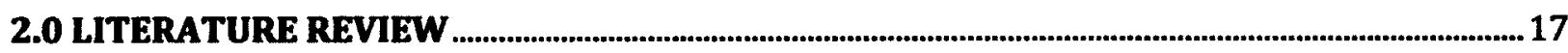

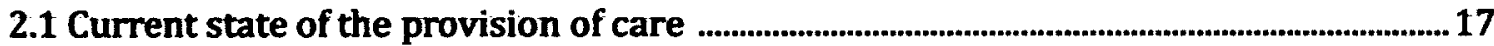



2.3 User design research for health technologies .................................................................................34

2.4 Summary of literature review .................................................................................................... 46

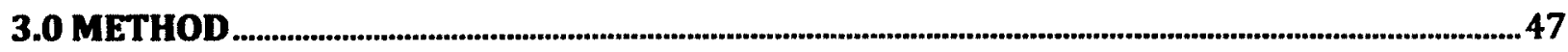

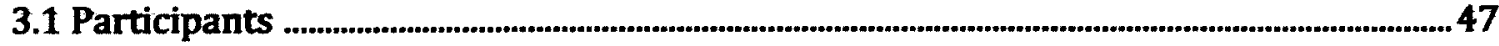

3.2 Materials and Apparatus ....................................................................................................................... 48

3.3 Design .............................................................................................................................................................49

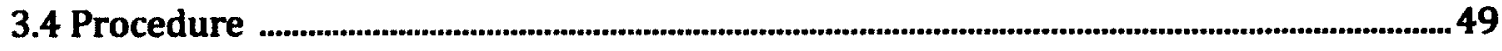

3.5 Qualitative data analysis ..........................................................................................................................51 
4.1 Research question one:

What are the main tasks and goals of the team workflow?

4.2 Research question two:

What are the current tools that support the workflow? 60

4.3 Research question three:

What in the workflow could be better supported by design? 66

4.4 Synthesis of findings: User needs .75

5.0 DISCUSSION

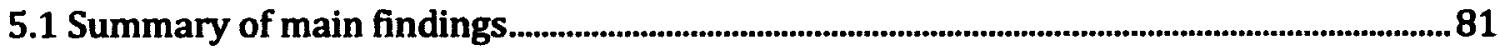

5.2 Practices in IPC geriatric rehabilitation ..................................................................................................85

5.3 Design insights and opportunities ................................................................................................86

5.4 The adequacy of the qualitative methods .................................................................................93

5.5 An approach to design insight discovery in IPC .......................................................................94

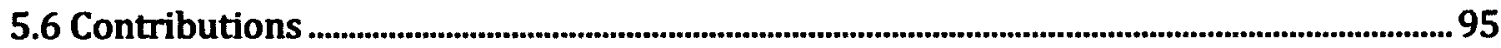

5.7 Future work ............................................................................................................................................................... 96

CONCLUSION

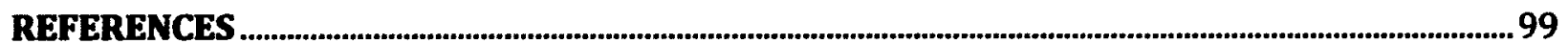






\section{LIST OF TABLES}

Table 1. Health technologies as described by Lehoux (2006) ..............................................................26

Table 2. Core technologies supporting aging in place by Pew and Van Hemel (2004) ................27

Table 3. Professions and number of participants in the study .............................................................48

Table 4. Coding sample of instances of tasks and goals descriptions ...............................................54

Table 5. Sample of artifact analysis; inconsistencies of content and design .....................................62

Table 6. Summary of key findings related to research question three .............................................. 74

Table 7. List of needs identified and emergent themes ............................................................................ 75

Table 8. Design Insights: Integrated assessment ...........................................................................................87

Table 9. Design Insights: Mobility performance monitoring ……............................................................89

Table 10. Design Insights: Collaborative discharge planning ................................................................90

Table 11. Design Insights: Patient and family discharge preparation....................................................91

Table 12. Design Insights: Communication and coordination......................................................................92 


\section{LIST OF FIGURES}

Figure 1. Three models of care practice compared ...........................................................................18

Figure 2. Current and desired state throughout the spectrum of patient care .................................21

Figure 3. The social and normative embeddedness of health technology design .........................36

Figure 4. The Goal-Directed Design process by Cooper ............................................................................... 40

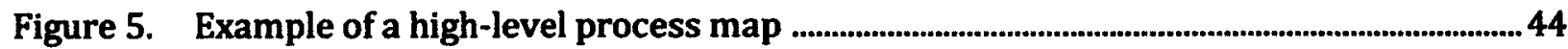

Figure 6. Example of a swim lane process map ............................................................................................... 44

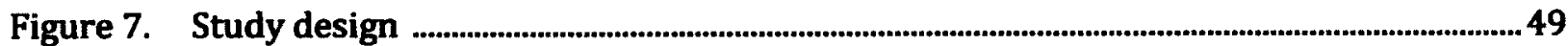

Figure 8. Qualitative data analysis process .....................................................................................................5 52

Figure 9. Comparative analysis of four professional workflows ...........................................................56

Figure 10. Swim lane process map representing one team workflow .................................................57

Figure 11. The 12 Bruyère Interprofessional Care Guidelines .........................................................................5 59

Figure 12. Sample of pictograms used in EBH geriatric rehabilitation unit ........................................61

Figure 13. Analysis of information needs of the four professions ............................................................ 65

Figure 14. Conceptual model of relevant activities and team interactions ............................................84 


\section{LIST OF APPENDICES}

APPENDIX A. Recruitment emails Phase I: inquiry interviews .................................................... 106

APPENDIX B. Recruitment emails Phase II: verification interviews ............................................... 109

APPENDIX C. Additional questions for those with knowledge of assistive technologies ........ 111

APPENDIX D. Debriefing script .............................................................................................................. 113

APPENDIX E. Informed consent form Phase I: inquiry interviews …................................................. 115

APPENDIX F. Informed consent form Phase II: verification interviews .......................................... 117

APPENDIX G. Email Instructions in preparation to Phase 1l: verification interviews .................. 119



APPENDIX I. Phase II: verification interviews script ........................................................................ 123 


\section{LIST OF ABBREVIATIONS}

CD: Contextual Design

EBH: Elizabeth Bruyère Hospital

EHR/EMR: Electronic Health/Medical Record

FIM: Functional Independence Measure

ICT: Information and Communication Technologies

IBM: International Business Machines Corporation

IPC: Interprofessional Care

HIT: Health Information Technologies

HFO: HealthForceOntario

NIST: National Institute of Standards and Technology

OACIS: Open Architecture Clinical Information System

PCMH: Patient-Centered Medical Home

PD: Participatory Design

UCD: User-Centered Design 


\section{GLOSSARY OF TERMS}

Interprofessional Care (IPC): The provision of comprehensive health services to patients by multiple health caregivers who work collaboratively to deliver quality care within and across settings (HealthForceOntario,2007).

New Product Development (NPD): A common term used in product design, engineering and business to refer to the overall process of bringing a product to commercialization (Koen et al. 2001)

User design research: Research conducted for the purpose of understanding potential users of products.

Tools/artifacts: In this thesis, the terms tool and artifact are used interchangeably. These terms refer to the physical and digital objects used to carry out the work on a daily basis, such as documents, forms, instructional pamphlets, databases, handouts, bulletin boards, etc. 


\subsection{INTRODUCTION}

"Great care means being able to provide optimally knowledgeable care at the right time and in the right way for people and not wasting resources... fundamentally you're talking about making teams that can go from being disconnected cowboys ... to pit crews that actually work together toward solving a problem." (Gawande, in interview with Alex Howard, 2012)

This thesis explores the intersections of the healthcare space and design. As the healthcare space finds its way towards a more sustainable provision of care and a pleasurable healthcare experience for clinicians and patients, design research opportunities emerge. New collaborative models of care are changing the requirements that information and communication tools must fulfill. Therefore, new product developers ought to understand these clinical processes and the emerging user requirements in order to develop innovative tools that fit seamlessly into the work practice. Adopting the skill sets of two user-driven design disciplines, Industrial Design and Human Computer Interaction to gain such understanding increases the possibility that solutions optimally support the needs of clinicians and patients.

Under traditional models of care professionals rarely collaborate and each professional generates parallel interventions. Each of professional keeps their own notes, in their own clinical terminology and rarely collaborates to formulate or carry out interventions. This results in a fragmented provision of care for the patient across the continuum (HealthForceOntario (HFO), 2010). This disconnected mode of practicing is rapidly being replaced by a more collegial effort, however, the technologies for information sharing and communication have not kept up with changes in working relationships. This thesis explores some of the reasons for this situation via a case study to understand a common workflow, the current tools supporting that workflow and the opportunities for design to improve this overall process, that can in turn, enhance the quality of care for the patient. 


\subsection{Background}

Older adults are prone to fracture their hip due to falls or osteoarthritis and often require hip surgery. This is a condition that often leads to loss of independence (Papadimitropoulos et al, 1997). Studies have also indicated that less than half of older adults who undergo surgery regain pre-fracture status and that the mortality rate among these patients ranges from $10 \%$ to $28 \%$ at 6 months post surgery (Keene, Parker, Pryor 1993). According to Statistics Canada, falls account for $84 \%$ of hospitalizations in older adults which represents an estimated cost of 2.9 billion annually for the healthcare system (PHAC, 2007). Consequently, hip fracture in older adults has become a major public concern (Naglie et al. 2002).

An older adult with a hip fracture often requires a dedicated level of rehabilitation care. In postoperative rehabilitation practice, a patient who has undergone hip surgery is often seen by various professionals including physicians, nurses, occupational therapists and physiotherapists in three main clinical settings: acute care, rehabilitation care and outpatient care. To respond to the demands that a frail population places on the healthcare system, strategies have been put in place for implementing interprofessional and patient-centered models of care (HF0,2007, HFO,2010; AAFP, 2008; Jones, Way and Baskerville, 2001). Under the new models, professionals are expected to collaborate within and across settings to provide one comprehensive plan of care. They must also consider the patient needs, values and preferences as drivers in those decisions (HFO, 2007; AAFP, 2008).

This new way of practicing is increasing the number of collaborative activities in which professionals' workflows intersect. For example, in geriatric rehabilitation units professionals have adopted joint exams and regular meetings and have started to implement new artifacts for collective use (Sainclair, lingard and Mohabeer, 2009). In the healthcare space, communication is highly asynchronous and must rely on efficient means of information sharing; therefore, tools for documentation and communication play a key role in the efficiency of the workflow and the professionals' job satisfaction.

An increasing number of studies demonstrate the opportunities that Health Information Technology (HIT) and Information and Communication Technology (ICT) present for increasing the efficiency of documentation processes, supporting the professionals' capacity to make 
timely decisions and providing remote treatment (Tang and Carpendale, 2009; Chan et al.,2009; Burk, 2012). However, current efforts are concentrated largely on means for streamlining information management, Electronic Health Records, being the most prominent, but less emphasis is placed on means for facilitating communication among healthcare professionals.

The healthcare space has lagged behind in the implementation of many of these tools (IBM, 2012; Leonard, 2004). This is due in part because many technologies are not mature enough to be introduced into the clinical practice (Hermens and Vollenbroek-Hutten, 2008). Many information technologies that are starting to proliferate have slow adoption rates. This, in many cases, has been associated with design shortcomings such as being poorly automated and slow (Robeznieks, 2005), adding extra work, being difficult to learn, as well, as introducing unanticipated workflow concerns (Harrison, Koppel and Bar, 2007; Bates, 2000; Tang and Carpendale, 2010). The reason many technologies fail may lie in the fact that, often, they are designed without a deep understanding of the user needs and the constraints that lie within the social, technical and organization of the healthcare space (Lehoux, 2006; Lucas, 1975). As a result, many products do not optimally support the needs of clinicians and patients. This knowledge can be gained through user design research.

User design research is employed to gain an understanding of the needs of potential product users (Suri, 2008; Cooper, 2007; Saffer; 2010; Norman, 1998). Approaching this type of research in a systematic way can generate rich descriptions of a work process, and point at weaknesses and gaps that products may be able to improve. User insights may contribute to improving the design of tools professionals need to perform, supporting the shifts towards the envisioned integrated provision of care, and ultimately, enhancing the healthcare experience.

\subsection{Statement of the problem}

The specific problem for this research stems from the fact that design researchers know little about the specific needs of clinicians, in particular, those that have emerged from the shifts in models of practice. As the healthcare system finds its way to a revamped provision of care, many designers are being called to participate in research and development projects in 
academia and industry to assist in the design of the next generation of health products and services.

In the area of healthcare and rehabilitation practices, there is limited understanding of the user requirements new products must meet to fit transparently into the various professionals' workflows and the daily lives of patients. There is a lack of understanding of how interprofessional teams work to provide care, for example, to a geriatric patient with hip surgery. More specifically, there is a limited documented on the main activities and goals in their workflows, the points of intersection, and the individual and collective needs. Thus, there is a gap in the knowledge of new product development regarding the specific design needs of professionals' collaborating in the area of rehabilitation medicine. This knowledge is crucial given the significant opportunities that technologies seem to have in increasing patient participation, in aiding patient-provider communication and in providing remote care. Such user-centered knowledge can improve the efficiency of documentation processes, facilitate the generation of comprehensive care plans, increase job satisfaction of healthcare professionals and, ultimately, improve the patient's quality of life.

As this problem can be found throughout the healthcare system, it makes sense to focus on a specific case that may give rise to design insights and that could be a useful example for other healthcare situations.

\subsection{Focus of the study}

The purpose of the present research is to investigate, through a descriptive case study, the tasks and goals of four professions involved in the care of geriatric patients with hip surgery. The specific work practice was scoped to the process from admission to discharge in a short-term geriatric rehabilitation unit. This was done with a view to identifying specific professionals' needs that may inform the design of information and communication tools.

The study followed a qualitative research design with professionals recruited purposively from the short-term rehabilitation unit at Elizabeth Bruyère Hospital in Ottawa, Canada. Descriptions of team practices and professionals' views were gathered through two phases of semi- 
structured interviews. In-depth document analysis was performed on the artifacts used by professionals in their daily practice. Institutional archival data were also analyzed.

\subsection{Study Constraints}

A user design research is best conducted by means of ethnographic field study techniques which involve observation of behavior and inspection of artifacts. The clinical setting in this case study presented limitations for using these techniques due to issues of information confidentiality, health risks and invasion of privacy. Furthermore, the process to obtain ethics approval for conducting research with patients extended past the time and resources available for this thesis. In-situ interviews were, therefore, chosen as the most suitable data gathering method.

\subsection{Significance of the study}

This research has significant implications for the design field. Professionals involved in the development of new technologies for rehabilitation including biomedical engineers, information technologists, and industrial designers, can find valuable insights into possible functions for and attributes of new applications. For instance, user insights about monitoring activities, discharge planning and patient training may contribute to the design of more suitable user-oriented information management and communication tools for remote rehabilitation care. Furthermore, design researchers can find insights on ways to conducting research in the healthcare setting. They may also identify specific research areas to further investigate as the design knowledge about clinical practices, professionals and patients increases.

Moreover, healthcare professionals transitioning into IPC practice may benefit from the models representing the collaborative team tasks and goals that resulted from this study to further the understanding of their new modes of practice. 


\subsection{Research questions}

Three research questions were addressed in the case study:

RQ1: What are the main tasks and goals of the team workflow?

RQ2: What are the current tools that support the workflow?

RQ3: What in the workflow could be better supported by design?

\subsection{Outline of the thesis}

There are six chapters in this thesis. Chapter 1 provides an introduction to the thesis and the scope of the work including the rationale for an interdisciplinary approach and explaining the gap this design research attempts to address. Chapter 2 contextualizes the thesis subject by presenting a literature review of the current state of affairs of rehabilitation practices, the opportunities and issues of health technologies and the recommended methods for research in this area. Chapter 3 describes the method adopted for carrying out the case study. Chapter 4 details the results of the study organized under the three main research questions posed. Chapter 5 discusses the design opportunities that emerged from the analysis, the contributions to the field of design and the future design research opportunities. Chapter 6 provides a conclusion. 


\subsection{LITERATURE REVIEW}

The literature review contextualizes the research questions described in the introduction chapter. It explores influencing trends and opportunities in the rehabilitation care practice as they relate to new product development. The literature review is divided into three subsections. The first one focuses on the discussion of the recent evolution of the healthcare systems and the current practice in geriatric rehabilitation care. The second one provides a discussion of the role of technology in rehabilitation practice. The last section discusses current approaches and methods used in the research and development of health technologies.

\subsection{Current state of the provision of care}

The following passages provide an overview of the evolution and the current state of health provision in Canada with a view to understanding the shifts and forces that influence healthcare professionals in rehabilitation practice. It includes definitions of team work in clinical care, a description of the state of affairs in healthcare in Canada, and specifics on the rehabilitation of older adults with hip surgery.

\subsubsection{Definitions of health teams}

Healthcare teams have only been identified as such in the last century and the concept of combining disciplines in practice began only after World War II, according to Olupeliyawa et al. (2009). As these teams developed many terms have been used interchangeably to define the level of collaboration among professionals. Some of these include parallel, multidisciplinary, interdisciplinary, interprofessional care. The differences might not always be clear. Therefore, for the purpose of this thesis, it is important to define some of these concepts..

Figure 1 below illustrates graphically the differences among parallel, multidisciplinary and interdisciplinary approaches to practice (Harrison and English, 2001). In a parallel practice, the individual disciplines work in silos to deliver care and there is minimal communication among them. In a multidisciplinary practice, the individual disciplines engage in some level of communication to inform decisions, however, each one sets its own goals and carries out individual interventions. In an interdisciplinary practice, individual disciplines work interdependently collaborating to making decisions together about the intervention and 
delivering one comprehensive plan of care (Yaffe, Dulka and Kosberg, 2001). In this latter mode, the clinical goals are shared, and therefore, they cannot be achieved without the complementary skills of the various disciplines involved (D'Amour et al., 2005).

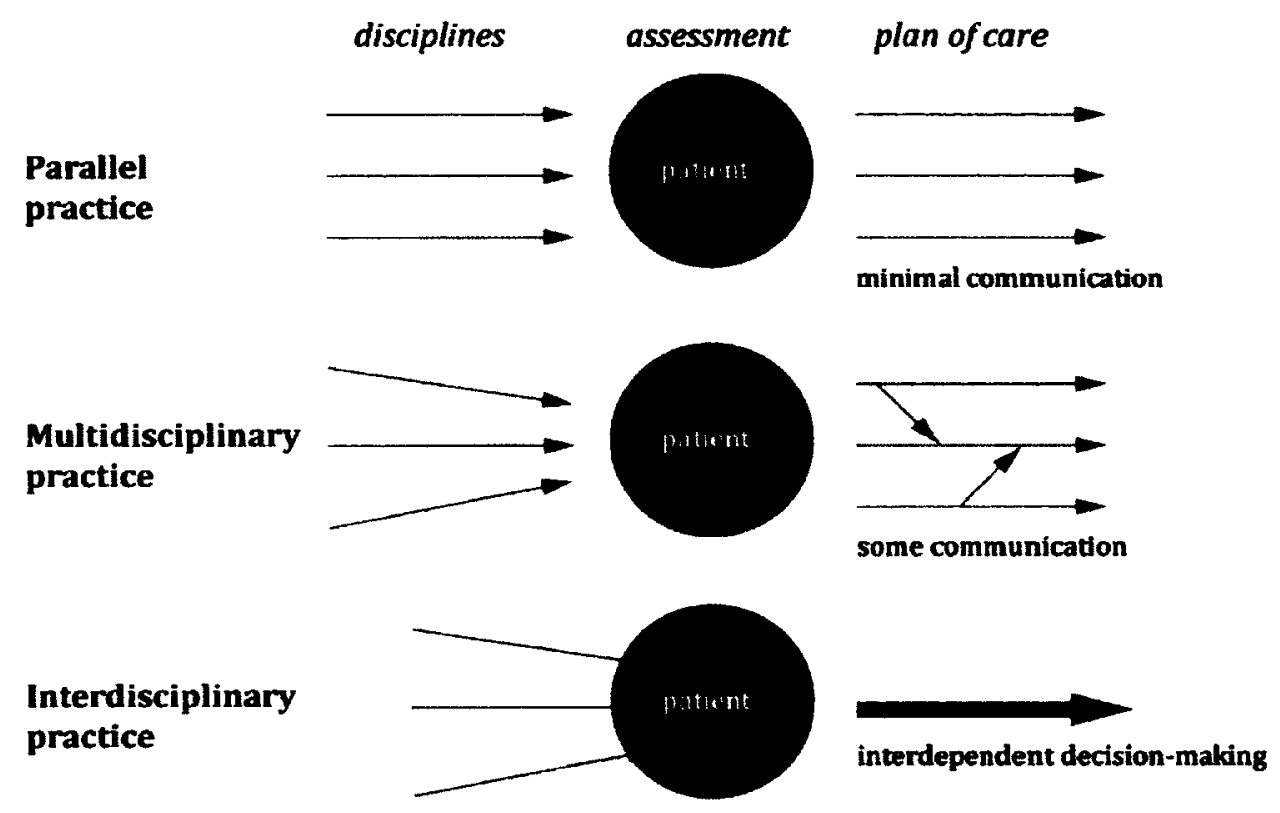

Figure 1. Three models of practice compared (Adapted from Harrison and English,2001)

The terms discipline and profession are also used interchangeably to refer to the various modes of practice. As defined by the Center of the Advancement of Interprofessional Education (2002) the term discipline refers to one's field while profession refers to one's vocation. Oxford Dictionaries Online defines "discipline" as a" branch of knowledge" and defines "profession" as "a paid occupation, especially one that involves prolonged training and a formal qualification" (Retrieved from oxforddictionaries.com). From these definitions and in the context of this research, it could be said that the main distinction between these two terms is that a discipline refers to the organized body of knowledge while a profession involves the regulations and licensing requirements for standardizing the methods of applying such knowledge. In these terms, a profession can be made out of various disciplines.

In the literature, the term interprofessional is more commonly used when referring to the interdisciplinary levels of collaboration established by health regulatory bodies. In Ontario's 
health reports the term Interprofessional Care has been abbreviated as IPC. Hence, this term and its abbreviation will be adopted throughout this document.

Research documenting the benefits of IPC is growing and competencies are being defined. Common to most models is the concept of patient-centeredness. There is no common consensus on the principles underlying the achievement of IPC, but organizations are creating guidelines to make it easier for healthcare givers to collaborate. In the Health Team model (Mickan and Rodger, 2005) core team competencies such as purpose, goals, leadership, communication, cohesion and mutual respect are described as key elements of effective team work. Furthermore, Vyt (2008) claims that to move to interprofessional teamwork, it is necessary to develop "a collective code of ethics, a shared complementary responsibility, effective team coaching and coordination of care planning and instruments that scaffold teamwork". The present investigation focuses on the last item in this list, that is, the instruments that support the teamwork of the interprofessional care team under study.

\subsubsection{Health teams}

In several industrialized countries, major pressures, such as the growing numbers of aging people, shortages of medical professionals and increasing cases of chronic diseases are pressuring health institutions. This situation is thus pushing health care providers, governments and policy makers to rethink the provision of care so that the healthcare system can respond effectively and efficiently to present and future demands. Emergent models of care place emphasis on patient-centeredness and prevention for which high levels of collaboration among healthcare providers are required. Initiatives such as the Patient-Centered Medical Home $(\mathrm{PCMH})$ in the United States aim at providing longitudinal care rather than episodic care in hospital settings (AAFP, 2008).

Major strides have been made in the last decade in Ontario to revamp the provision of care for citizens to have access to the "right number and mix of qualified healthcare givers" (HFO, 2010). In May 2006, HealthForceOntario (HF0) was created. At its core it is a multi-year strategy to transform the provision of care with emphasis on interdisciplinary practice. HFO funding programs are engaging partners in education and healthcare to develop "skilled, knowledgeable caregivers and create healthcare delivery teams that will make the most of their abilities" (HFO, 
2010). In 2007, Interprofessional Care: A Blueprint for Action in Ontario was developed to create a framework and guide health institutions into implementing interprofessional models of care. Interprofessional practice requires professionals to be involved in interdependent goal-setting, sharing of responsibility, respecting and relying on each other's competences and evaluating the outcome collaboratively so that a comprehensive plan of care can be provided (Yaffe, Dulka and Kosberg ,2001; HealthForceOntario, 2010).

As described in the Interprofessional Care: A Blueprint for Action in Ontario, the current provision of care is fragmented. Figure 2 shows the difference between a current fragmented care and the desired seamless care. A patient going through surgery will often go through three settings, namely acute care, rehabilitation care and community care. In each of these settings, the patient would see a professional or team of professionals who will support the recovery process. At present, communication among professionals within and across settings is limited or non-existent. Therefore, the patient sees various disconnected teams working independently and asking similar questions at each transition. The ideal provision of care is seamless for the patient. This can only be achieved when there is constant dialogue among professionals within and across settings to deliver one cohesive plan of care throughout. In this view, the patient is cared for by one team across the continuum.

Interprofessional Care as described in Ontario's new policies (HFO, 2007) is "the provision of comprehensive health services to patients by multiple health caregivers who work collaboratively to deliver quality care within and across settings". The key aspects of this collaboration are illustrated by Jones, Way and Baskerville (2001) definition "the process of communication and decision-making that enables the separate and shared knowledge and skills of health providers to synergistically influence the client/patient care provided". 


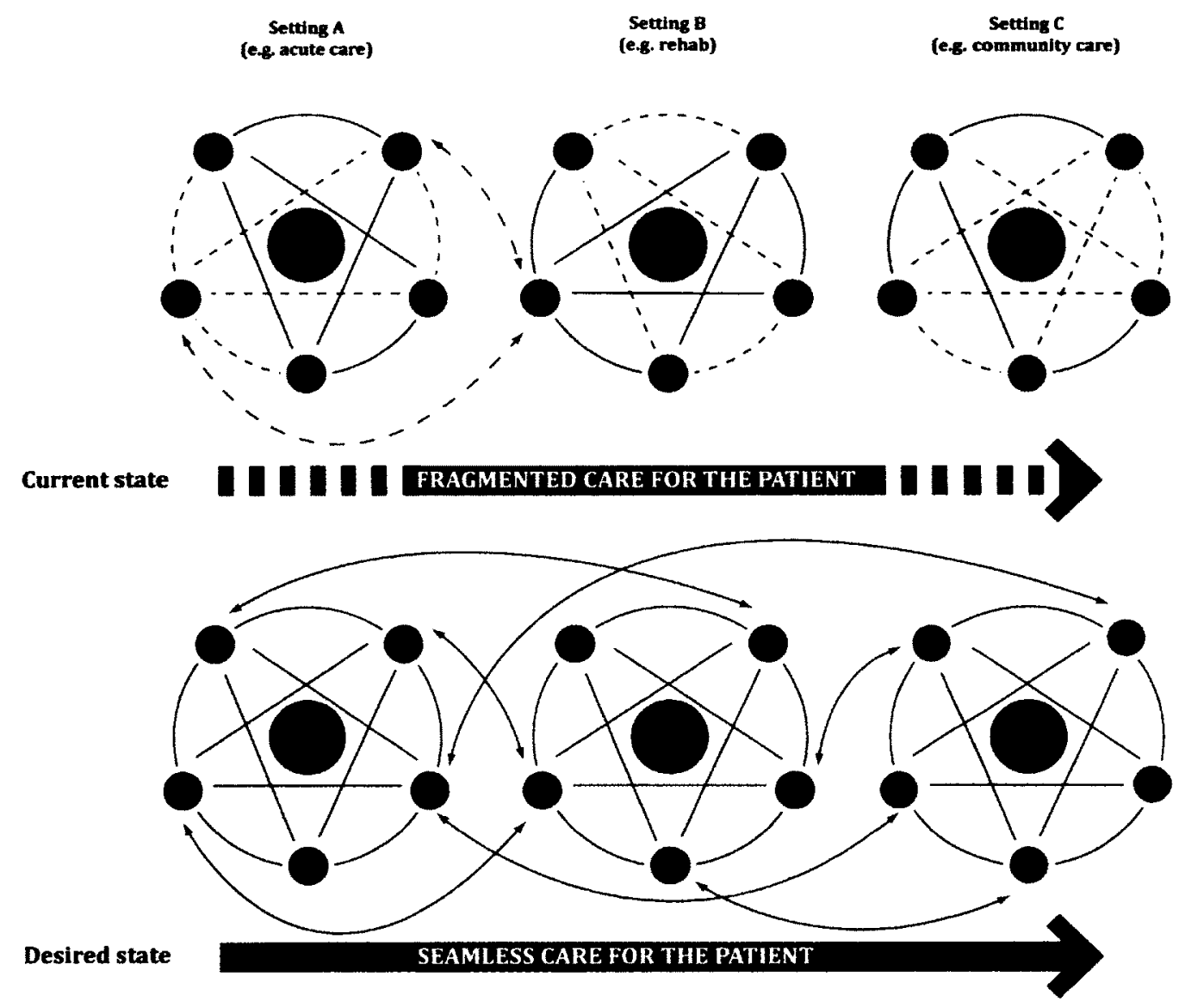

Figure 2. Current and desired states throughout the spectrum of patient care (Adapted from Interprofessional Care: A Blueprint for Action in Ontario, HFO, 2007). Dots depict health caregivers. Broken lines depict minimal communication between settings and among professionals and patient. Solid lines depict constant communication and interaction as a result of interprofessional care practices.

In Ontario, rehabilitation units are leading the implementation of IPC practice. Sainclair, Lingard and Mohabeer (2009) conducted an ethnographic study of a spinal cord rehabilitation care unit in Toronto, Ontario, in which there was clear evidence of a strong IPC supported by clinical, cultural and organizational factors. Two dominant themes emerged from this study: team culture (leadership, care philosophy, relationships and the context of practice) and communication structures (formal and informal) are driving the IPC practice.

Team-based strategies have been found to help efficiently manage the complexity of conditions in geriatric, palliative and mental patients' health. Many institutions have organized their teams 
to address the particular needs of geriatric patients and are starting to gather evidence of the benefits of IPC. These benefits have been associated with improved health outcomes in geriatrics, rehabilitation and orthopedics (Strasser et al, 2008; Reeves et al 2001). Thus, from the design perspective, professionals working in geriatric rehabilitation units may provide an insiders' view of the daily IPC practice. This was one reason for selecting a well-established geriatric unit as the subject of study.

\subsubsection{Hip surgery rehabilitation care}

A common type of geriatric case requiring a collaborative model is the care of patients who have undergone hip surgery. Older adults often require hip surgery as a result of falls or osteoporosis, which seems to send their health condition spiraling downward (Papadimitropoulos et al, 1997). Statistics indicate that less than half of older adults who undergo surgery regain pre-fracture status and that the mortality rate among these patients ranges from $10 \%$ to $28 \%$ at 6 months post surgery (Keene, Parker, Pryor 1993). A majority of older patients require continuous post-surgical care. This in turn places a higher burden of care on the healthcare system (Seniors Falls Canada, 2005). According to Statistics Canada, falls account for $84 \%$ of hospitalizations in older adults and this represents an estimated cost of 2.8 billion annually. Consequently, hip surgery in older adults constitutes a major public health issue for the Canadian healthcare system (Naglie et al, 2002; Marottoli et al, 1992).

Hip surgery is followed by an intensive process of in-patient or short-term rehabilitation activities and continues until functional performance returns to the pre-operative state. As defined by a report generated by the government of New South Wales in Australia (NSW Health, 2010), rehabilitation care is the provision of care that aims to:

- restore functional ability for a person who has experienced an illness or injury

- enable regaining function and self-sufficiency to the level prior to that illness or injury within the constraints of the medical prognosis for improvement

- develop functional ability to compensate for deficits that cannot be medically reversed

Challenges of patient flow and the ability to provide quality care are discussed in the literature. Studies in rehabilitation units demonstrate efforts to increase the capacity to provide quality care by finding ways to efficiently manage patient flow in inpatient units. For example, Alberta 
Health Services (n.d) explored ways for improving the home discharge process from provincial neuroscience units. These authors demonstrated that implementation of processes and protocols such as interdisciplinary discussions, visual management tools, a discharge checklist, patient and family educational materials, as well as discharge summaries improved the efficiency of the unit. In this case patient discharges increased from $20 \%$ to $76 \%$ within one hour of the decision. The study also demonstrated improved patient and family satisfaction. Sinclair et al (2009) found that having a common team purpose of optimizing independence and functioning in preparation for patient discharge resulted in effective shared planning and delivery of care.

Another case study in Australia examined the usefulness of a utilization review tool called InterQual to support the selection of patients and the timing of transfer from acute care to rehabilitation (Poulos, $\mathrm{C}$ et al, 2011). The goal of this study was to determine the adequate level of care needed from acute care to rehabilitation. It focused on inpatients in acute care with stroke, hip fracture or elective joint replacement. This study concluded that the utilization review tool could play a decision-supporting role in the determination of medical stability for the rehabilitation team. The above discussion underscores the importance of managing the transition from hospital to home. This is a critical juncture for providing continuous and consistent care that supports the patient throughout the rehabilitation journey (Castillo and Hall, 1987) and, therefore, requires attention.

From the point of view of design, these studies provide evidence of the need to develop and implement tools that increase the efficiency of the clinical processes in order to manage patient flow and improve the provision of care. Moreover, they provide insights about the type of tools that could be inquired about in the present study.

Up to this point, the review of the literature provides three important concepts that this research must consider in the understanding of the practice: the goals of rehabilitation care, the pressure to discharge patients quickly, the need for decision-supporting tools to help in this process. 


\subsubsection{Elizabeth Bruyère Hospital Short term geriatric unit}

The geriatric unit at the Elizabeth Bruyère Hospital (EBH) in Ottawa was chosen for the investigation. This brief description contextualizes the work environment of the professional team under investigation.

The EBH has a short-term geriatric unit with 90 beds. A 30-bed unit is dedicated to inpatient stroke rehabilitation and a 60-bed unit provides geriatric rehabilitation care to patients over 65 years old who are experiencing a loss of ability to care for themselves (Bruyère Continuing Care, n.d ). A basic team requires a minimum of four professions to which others may be added depending on the patient's condition. For a post-operative hip surgery patient the team often consists of a physician, a nurse, an occupational therapist and a physiotherapist which treats the patient for about four weeks. These patients come from acute care with a partial weightbearing status and are discharged home or to a long-term care facility, as required.

In 2008, the institution developed a set of guidelines to move the practice into IPC. These guidelines give teams some autonomy to determine how procedures in the unit are carried out. (Bruyère Continuing Care, 2010) For example, they can decide the precise professions that participate in performing the integrated assessments. They can determine that the nurse, the occupational therapist and the physiotherapist should carry out an admission mobility assessment. This type of participatory approach to update care practices facilitates implementation and provides for customized practices that meet the specific needs of the patient and the institution.

In sum, the preceding sections reviewed the current trends in the provision of care and rehabilitation practice, particularly in Canada demonstrating a transition of health care delivery with an emphasis in collaborative practices. In geriatric care, professionals deal with pressures to discharge patients quickly, while still ensuring they are functionally capable and safe. Professionals working in geriatric rehabilitation units are leading implementation of collaborative practices. Professionals in these units may provide greater insight into the ways the process is carried out in daily practice, a knowledge that is essential for new product developers. Additionally, the literature revealed that hip fracture in older adults constitutes a major public health concern in Canadian society. Therefore, it is a 
valuable condition to investigate. This understanding informed the decisions on the present thesis to focus on geriatric patients who had undergone hip surgery and the associated interprofessional care team at the $\mathrm{EBH}$ geriatric rehabilitation unit.

\subsection{Technology in geriatric rehabilitation}

As healthcare practices evolve, health management and prevention of health conditions in the elderly have become increasingly of interest to technologists and designers. Consequently, the following section reviews the literature about technologies in rehabilitation. It reflects on the challenges and opportunities for supportive technologies in rehabilitation care of older adults. The literature explains the concept of health technology and describes the opportunities for technology in supporting clinical workflows and Electronic Health Records (EHR). It also addresses the challenges for adoption of technologies in general, and health technology in rehabilitation.

\subsubsection{Health technologies defined}

This section lists some of the many technologies that are being discussed in the clinical processes and in the care of older adults. Since the subject of this investigation emphasizes the tools for clinical processes it is necessary to first frame what they are and what they do.

The following table presented by Lehoux (2006) clarifies the concept of technology within the specifics of healthcare and provides assistance in understanding the purposes and reasons for their desirability. She identifies eleven types (Table 1) that include : screening tests, diagnostic tests and imaging devices, monitoring systems, implants, surgery and therapeutic devices, palliative technologies, drugs, health promotion technologies, occupational health technologies, technical aids and information technologies. Particularly relevant for this research are those that the descriptions of which seem to pertain directly to the clinicians' workflow in rehabilitation care of hip surgery: diagnostic tests and imaging devices, monitoring systems, surgery and therapeutic devices, technical aids and information technologies. 
Health
technologies

Screening tests
$\begin{aligned} & \text { Diagnostic tests and imaging } \\ & \text { devices }\end{aligned}$

Monitoring systems

Implants

Surgery and therapeutic devices

Palliative technologies

Drugs

Health promotion technologies

Occupational health technologies

Technical aids

Information technologies

\section{What they do}

Where their desirability lies

Provide information that requires a confirming procedure or test (diagnostic)

Provide information about the presence/absence of disease

Provide information about various vital bodily functions, psychosocial well-being, and compliance with treatments

Restore (temporarily) bodily functions (e.g. cardiac functions, hearing)

Stop or delay the pathological process and reduce symptoms

Substitute (temporarily) natural bodily functions (e.g., breathing. nutrition, cardiac functions)

Stop or delay the pathological process reduce symptoms

Promote/discourage lifestyles and behavior; protect from or reduce harm associated with risky practices (e.g., drugs, sexuality, sports)

Protect workers' health; promote/discourage work-related behavior affecting health

Facilitate autonomy, mobility, and social integration

Record, archive, transmit, and provide access to administrative and clinical information
Information is valuable in ttself and/or it leads to a diagnosis in a timely manner

Information is valuable in itself and/or it leads to an appropriate and timely action vis-dे-vis disease

Interpretations of the data is reliable and leads to it being acted upon in an appropriate manner; continuous surveillance does not alter identity and behavior

Long-term risks, quality of life and identify alteration are acceptable to the patient

Risks, invasiveness, and consequences are acceptable to the patient

Sustaining life when quality is compromised is valuable

Side effects and quality of life are acceptable to the patient

Alterations of practices, identity, and peer recognition are acceptable/meaningful to the individual/groups

Overall quality of work conditions and alterations of practices, identity and peer recognition are acceptable/meaningful to the individual/groups

Aids are user-friendly and help overcome the social barriers associated with the disability

Access to and use of information respects confidentiality and brings efficiency and quality to health care.

Table 1. Eleven types of health technologies indicating what they do and the reasons for their desirability according to Lehoux, 2006. 
With that understanding, it is also important to look at other technologies associated with the care of older adults. For this, Pew and Van Hemel (2004) table 2 is used. It summarizes core technologies and their capabilities to enable patients to age at home. The most relevant for the context of the present study are: biosensors and bodily diagnostics; activity sensors and behavioral diagnositics; personal health informatics; and agent, assistants, coaches, and companions.

Technology
Wireless broadband
Biosensors and bodily diagnostics
Activity sensors and behavioral diagnostics

Information fusion and inference engines

Personal health informatics

Ambient displays and actuator networks

Agents, assistants, coaches, companions

Adaptive, distributed interfaces

Remote community and collaboration
Values to Aging in Place

Anywhere in the home, any device connectivity

Rich and multiple streams of health information delivery

Real-time, routine chemical analysis

Targeted drug delivery and effects analysis

Location, objects, and person tracking around the home Regular activity and activities of daily living measurement and assessment

Personal baselines and alerts to meaningful deviations Reliable data even from temperamental technologies

Central repository for personal and professional health information

Tools for easy visualization of long=term trends

Lightweight ways to notice "okayness" of loved ones Smart home controls of all devices and appliances

Reminding and coaching of activities of daily living that are declining

Companionship for intellectual stimulus and support

Any device interactivity - do not have to use a personal computer to computer Interface experience personalized fro familiarity and function

Multiple modes and media for communicating across distance

Ways of representing and feeling "presence" at lonely times

Table 2. Core technologies supporting aging at home (Pew and Van Hemel, 2004).

A myriad of technologies have been rapidly developing to support healthcare processes. Some of the technologies that may offer opportunities in the rehabilitation care of geriatric patients with hip surgery concerning clinicians work include: diagnostic tests and imaging devices, monitoring systems, surgery and therapeutic devices, technical aids and information technologies; and concerning both patient and clinicians include: biosensors and bodily 
diagnostics; activity sensors and behavioral diagnostics; personal health informatics; and assistants, coaches, and companions for patients.

\subsubsection{Facilitating clinical workflows}

These technologies are in constant evolution. A question of considerable interest for new product developers concerns how they fit into clinicians' daily routines. A great deal of effort and resources are allocated to the development of health technologies. Leading companies in health products, such as IBM and Philips, are engaged in research and development programs directed toward the application of technology to transform the provision of healthcare services. IBM's Watson system has recently earned a lot of attention and interest among technologists. On its website, the IBM Corporation describes it as the next-generation cognitive computing system with capabilities in "natural language processing, hypothesis generation and evaluation, and machine learning". It is said to be a 'game changer' in transforming the vast amount of data emerging from health research into practical decision support information for clinicians to be able to deliver evidence-based diagnosis and treatment suggestions. This demonstrates that there are new systems with the capability to turn the vast amount of clinical data into meaningful information the professionals can use to aid decision making. This creates an opportunity for design researchers to determine what is relevant for clinicians and defining effective ways to deliver information when they need it, in a format that they can use when formulating interventions.

Projection into the future of the trends emerging from the rapid technological advancements of this type leads to a vision of a highly sophisticated healthcare service coming into existence with the assistance of integrated tools. Harnett (2011) describes a scenario of the ideal workflow in the provision of primary care in the near future:

Each day he [the primary care physician PCP] logs into his service portal using biometric ID on a lightweight and durable tablet PC. Here, all appointments are listed, clearly marked are those that are virtual. For each patient a click of the mouse displays a summary about the patient. Every patient is required to answer a short questionnaire prior to the visit that can be [done] from home or in the waiting room. If the patient has specific questions the Clinical Support System (CSS) automatically pulls relevant data from trusted sources. For those that utilized home health monitoring equipment, the data is automatically sent to the Electronic Medical Record and 
summarized by the CSS. Prior to being posted on the physician portal, members of the clinical team review the appointment file and append the data. Based on the reason for the visit, the CSS presents questions and options for a care plan. Historical data can be immediately accessed on the tablet PC and shown to the patient 'If-then' scenarios can be run with projected outcomes. If routine tests are due a flag is displayed. A click of the mouse sends a message to the patient: email, phone or both depending on user preferences. If appropriate, the patient encounter posts de-identified data to central registries and public health agencies. The CSS suggest a certain medication based on research outcomes, and matched against current medications and allergies, prescriptions are sent as well with a reminder with possible side effects to watch for. Using Natural Language Processing (NLP), the physician adds notes that are transcribed to the EMR At the end of the visit, the patient checks out and reviews an encounter summary. Diagnostic and billing codes are generated and are forwarded to the billing application. Even after the patient leaves, continual communications occur between the clinical team and the patient. If parameters exceed a predetermined range, alerts are sent. Over time, the condition of the patient is mapped [...] For the virtual visits, the encounter is performed using software video applications similar to online meeting tools used by corporations regularly. Select[ed] data and images can be pushed to the patient [sic] (Harnett, 2011:19)

A case in point is a recently developed application for oncology diagnosis and treatment created in collaboration with Memorial Sloan-Kettering Cancer Center in New York. According to IBM (2013), the center has consolidated clinical expertise, molecular and genomic data, and a vast repository of cancer case stories. It has designed an application to analyze and reduce the data to meaningful points. It is available to oncologists and provides suggestions, supporting evidence, and recommendations about the kind of information needed from the patient. Two key user interface successes of the product are that it is equipped with voice recognition technologies and is presented on a portable tablet. It also has administrative capabilities of communicating with insurance providers to arrange details on delivery of care.

The development of these technologies is making the transformation real. The multiple emerging technologies, the envisioned scenario and this oncology case study provide evidence of technology opportunities for the application of technology to enhance clinicians' capacity. They show that an understanding of a clinical workflow and the context of use contribute to defining the potential for new technologies. This can only be achieved with a close 
understanding of the workflows of the individual clinicians, as well as their various points of intersection, in their particular context.

\subsubsection{Electronic Health Records}

Communication is highly asynchronous in the clinical setting, that is, that it does not occur in fixed intervals or sequence. As such, information management mechanisms have become a focus for new product developers. The transition from paper-based to electronic records is imminent (Horsky et al, 2012; Sainfort et al, 2008; Terry et al, 2012; Hayrinen, 2008). Close to the mainstream is the implementation of Electronic Health Records (EHR) also called Electronic Medical Records (EMR). Health information and communication technologies have been developed and adopted rapidly by health institutions in recent years and have become an essential way to manage patient information. This demand has encouraged a proliferation of EHR systems from multiple providers. Many of these have been designed to become competitive in the industry but not necessarily with an understanding of clinical needs. This is a problem that leads to low adoption and possible risks for patients as discussed in the next section. Finally, the designers of EHR systems have devoted particular attention to facilitating management of information for physician and nurses (Tang and Carpendale, 2009b), but often neglect other professionals such as physiotherapists and occupational therapists as additional primary users of the system.

\subsubsection{Challenges of technology adoption}

The issue of slow adoption rates of health technologies has gained interest among health informatics researchers as they attempt to identify the reasons for this. One of the reasons reported is that they slow down the process (Robeznieks, 2005). Other issues reported being difficult to learn, having limited electronic connectivity, and scanning capabilities (Terry et al, 2012), this in turn sometimes results in the creation of workarounds or even leads to abandonment. Moreover, technology designs also bring with them unintended consequences (Tang and Carpendale, 2010). Campbell et al (2006) examined five settings using Computerized Provider Order Entry systems and identified nine types of these consequences:

- More or new work for clinicians

- Unfavorable workflow issues

- Never-ending system demands 
- Problems related to paper persistence

- Untoward changes in communication patterns and practices

- Negative emotions

- Generation of new kinds of errors

- Unexpected changes in the medical power structure

- Over-dependence on the technology

Wu et al, (2008) argue that the perceived ease of use has a direct effect on the usefulness of technology. In other words, if clinicians do not find it easy to use, they doubt they can trust it. These, objectively speaking, have nothing to do with a given system's usefulness, but with usability and trust. These issues could be possible explanations of reported job dissatisfaction and low technology adoption rates. Additionally they give rise to concerns about the increasing likelihood of medical error (Pennsylvania Patient Safety Authority, 2012). As a response to these issues, in the United States, the National Institute of Standards and Technology (NIST) has recently established minimum standards for software development, such as EHR and DSS, thereby ensuring that design processes involve a user-centered design approach (Chapman, 2013).

Another important aspect is the impact of digital records on the interaction with patients. It is becoming evident that the data entry processes are not well integrated with the assessment activities. Verghese (2012) asserts that, in the same way that technology has been brought to the bedside to provide consistent care, it will be important to find the best way to integrate data entry into EHRs more seamlessly during the actual exam. In his words, "Having portable computers is a bit of a help but I think even more, technology might come to a point where we have scribes or automated ways in which the entire encounter is captured so you don't have to go back and recreate it digitally" (Verghese, cited in King 2012, p. 1).

Shared care plans and decision support systems have received some attention in the literature, particularly in clinical studies of interprofessional care. Tang et al. (1995) conducted contextual inquiry with clinicians in ambulatory care. Their study revealed five needs: integrated access to patient information, summary information (e.g, problem lists, medication, demographics), reliable communication among health team members to coordinate, track and manage care of 
individual patients, tools to support patient instruction and education, and convenient access to computer workstations with good training and technical support. Patient education and coaching is gaining more attention and some socio-technical studies have started to provide evidence of the benefits of technologies to health outcomes. Communication and coordination, however, have notably received less attention in the literature of health applications and, therefore, may offer the most significant opportunities for design.

The above discussion reflects many of the efforts being undertaken in developing technologies to enable integrated patient data management. Despite the exciting opportunities technologies seem to offer, technology adoption has generally been met with resistance by the healthcare sector according to the literature (Leonard, 2004). In the present investigation, professionals' views about current tools may offer further insights into the reasons behind the slow adoption of technologies in clinical settings.

\subsubsection{Health technologies in rehabilitation}

The International Classification of Functioning (ICF), a mandate of the World Health Organization (WHO), (ICF-WHO, n.d,) states that mobility assessment needs to include measures of capacity: what a person can do under standardized circumstances; and performance: what a person really does in daily life. It further explains that the mechanisms must account for body functions, activities and actual movement behavior in daily routines (Ziljtra, 2011). While various existing tools assist clinicians in capturing body functions and some activities under controlled conditions, there is much less support for capturing actual movement behavior in daily routines.

A growing body of literature citing visions and opportunities for moving the provision of care to the home is sparking discussion of new paradigms for clinical rehabilitation (Winters, 2002; Chan et al., 2009). In the field of biomedical engineering, the literature exploring the technical capabilities of monitoring technologies to assess mobility shows possible new applications specific to rehabilitation. These include remotely monitoring mobility and remotely supervising treatment (Hermens, Vollenbroek-Hutten, 2008). The same authors report, however, that many telemedicine technologies are "hardly mature enough to create robust Remote Monitoring Technology (RMT) systems that can be used in daily health care practices." A concern often raised regarding the implications of the use of technologies to monitoring behavior and daily 
activities is the level of invasion to patient's privacy, this is because once data is recorded it is easy transferable and therefore be subject to public scrutiny. It is a challenge that new product developers must be aware of and must address by setting sensible boundaries between what activities and behaviors can and should be monitored and what should be kept private. This is a serious matter that must be carefully considered, however, it is beyond the scope of this thesis to discuss it in detail.

Many of the envisioned applications for remote monitoring are possible through sensor-based technologies, including wearable sensors and others embedded in the environment. Sensorbased technology research goes as far as to envision smart environments that can gather data from several sources in the dwelling and track patient's activity levels (Crispim-Junior et al, 2012; Dishman, 2004). However, a major challenge often cited in sensor-based monitoring technology studies is data reduction and interpretation. Winters (2002) states that "there is a need for greater focus on the process and form for providing information to clinical decision makers. This includes approaches for more aggressively reducing, synthesizing and presenting data." Cooper et al, (2008) argues that:

our ability to collect data greatly exceeds our ability to utilize data to make clinical decisions.... What is needed; is not just tools for analyzing sensor data but tools which allow clinicians to integrate large amounts of quantitative sensor data with the limited qualitative data obtained during clinical visits (Cooper et al. 2008).

As the concept of telerehabilitation evolves among rehabilitative bioengineers, there are challenges specific to physical rehabilitation that need to be addressed. One of the dilemmas discussed in the biomedical literature is that current in-practice assessment processes depend on sporadic face-to-face meetings. These rely on observations and self-reporting methods, which do not necessarily capture the patient's functional performance in his or her home environment (Cooper et al., 2008). This is reinforced by other authors who have noted that clinicians could benefit from technological support tools for analysis, evaluation of outcomes of intervention, and prediction of risk of falls (Ziljstra, W. Becker, L. Pfieffer, 2011). Another issue is that tools for clinical assessment vary among disciplines and there is a need to develop uniform and standardized tools to allow for comparison of results over time and between providers (Winters, 2002). It is evident that, there is a need to develop quantitative and 
objective outcome measures that integrate clinical rating scales to facilitate the diagnosis, treatment planning and outcomes assessment.

It is clear from the above discussion that health technologies to support rehabilitation care are still in their infancy (Winters, 2002; Cooper et al, 2008). Many remote monitoring technologies are not mature enough to be applied in clinical practice. More studies would need to be done to understand how to turn the enormous amount of data that is possible to capture into meaningful and relevant information that clinicians can use to support their decisions. It is not surprising that health practitioners and health professional societies take a cautious approach toward delivery of clinical rehabilitation services based on technology-motivated arguments.

This whole section 2.2 has reviewed the literature on technologies supporting rehabilitation practice. It revealed that opportunities for technologies to facilitate a variety of information management, advisory, and diagnostic functions, have been a subject of investigation. However, it also revealed that many of these technologies, in particular, technologies that include monitoring capabilities, are far from being implemented into clinical rehabilitation practice.

The literature search provided only little evidence-based research in relation to professionals in rehabilitation care settings. This thesis is, therefore, beginning to fill an important gap in the literature of clinical tools for rehabilitation. Hence, this study focuses on clinical teams in rehabilitation practice, and places emphasis on identifying the opportunities for developing ways to assess and monitor patient functional performance. With this understanding, it may be possible to make recommendations that would address some of the issues noted, such as the limitations for: evaluating outcomes of intervention, and predicting risk of falls, comparing results over time and between providers, reducing, synthesizing and presenting data succinctly, integrating data entry into EHRs more seamlessly during the actual exam.

\subsection{User design research for health technologies}

In order to conceptualize technologies it is necessary to understand the theory on approaches to design. Some of these are discussed to inform the choice of approach for the present investigation. 


\subsubsection{The socio-technical perspective}

There are three main schools of thought about the relationship between technology and humans. On the one side is technological determinism, that is, the belief that technology shapes human action, on the other is the social perspective that argues that human action shapes technology structure in an iterative process which takes place both in initial development and after production (Bijker, Hughes \& Pinch, 1989). In the middle, is the technology-in-practice perspective which stresses that technology forms "a specially unbounded and heterogeneous network in which humans and other technologies incessantly interact according to a certain distribution of skills, tasks and responsibilities" (Lehoux, 2006, p. 51). The latter perspective is advocated for the conceptualization of health technologies at a macro level for policy-making.

Understanding the role of design within the complex health space is essential when conducting user research for health technologies. Figure 3 depicts such space. Lehoux (2010) illustrates three main categories (in dark boxes) that are key in the development of new technologies: designer, society and users. In the following figure, 'designers' are all those directly involved in the shaping of an innovative product. The 'society' box represents the macro societal trends, opportunities and perceived needs. The 'users' box represents all clinical experts and lay uses for which technology is intended. There is confluence between the three actors and the technology and the constraints of the healthcare space. Lehoux positions designers as central as they bring desires, values, intentions and expectations into concrete technologies users can apply. 


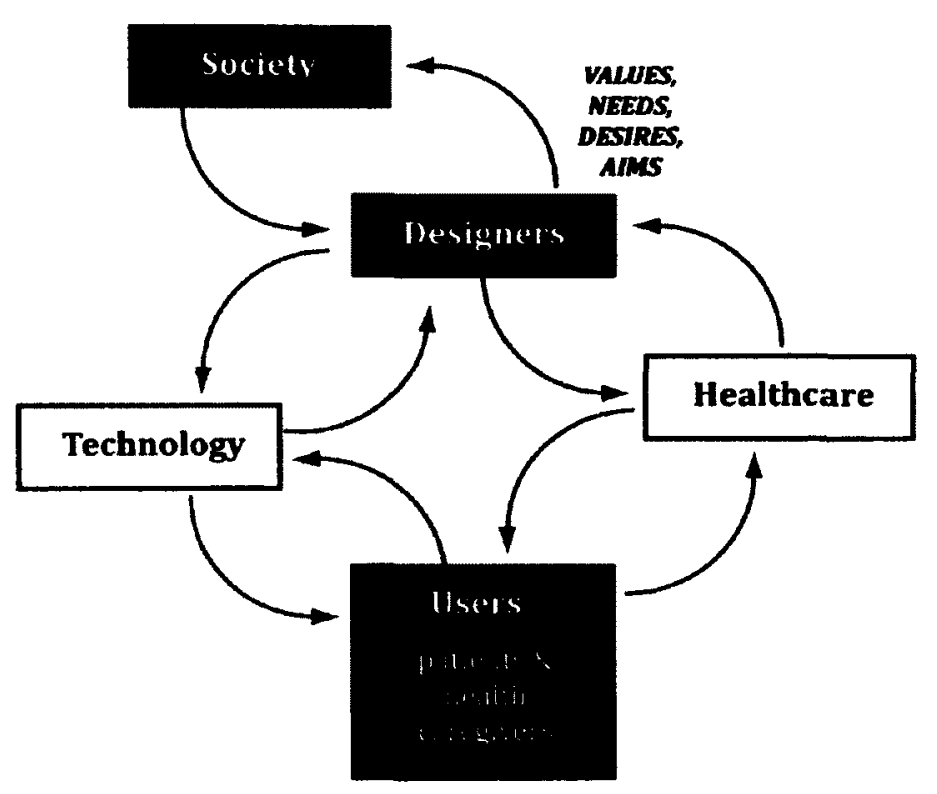

Figure 3. The social and normative embeddedness of health technology design (Adapted from Lehoux, 2006)

However, many people in the category of 'designers' do not realize their role when working at the micro-level. Lehoux asserts that at present "the extent to which health technology designers are perceived as being truly knowledgeable about healthcare practices is a matter of considerable debate". And she stresses that designers change society through technology; therefore, making technologies desirable is about more than merely meeting user's needs. A pivotal aspect of any design process is to oscillate between what is and what could be, and what is and what ought to be so as to embody values and intentions of the final users (Lehoux, 2006).

The latter statement highlights the perspective driving some of the decisions in this thesis: understanding the current normative process of rehabilitation practice as well as the current technologies used, and using this knowledge to envision what technologies could be, and more importantly, what these ought to be to align with the clinicians' values. But how do designers do this? In the design field, this type of approach is recognized as user-centered design. 


\subsubsection{The user-centered design approach}

Design fields such as industrial design and Human-Computer Interaction use human action as the basis for developing new products. User-centered design (UCD) and participatory design (PD) approaches have been adopted in these fields to bring users views into the various stages of the design process (Sanders \& Stappers, 2008). A UCD approach takes into account the specific needs of a group to make design decisions but may not necessarily involve users in the creation of the solution. A PD approach brings users into the design process as active participants (Schuler, 1993, Sanders \& Stappers,2008; Bødker, Kinsing and Simonsen, 2004). The way Sanders (2006) explains the difference is that in a user-centered design approach design researchers are seen as experts designing 'for' people, and these people are referred to as a subject, user or consumer. For example in UCD users may be first observed and interviewed as they do their work to identify their needs, and later they are asked to test prototypes of product concepts. In participatory design, researchers see others as the true experts in their domains, and therefore, they are generating designs 'with' people (Beyer and Holzblatt, 1998; Sanders, 2006). For example in PD, they may be brought in to give ideas on what a product could do or how it should be designed. These two approaches contribute intrinsic value to the development of successful technologies in contemporary design practice. The principles of the UCD approach are drivers in this investigation to identifying the needs of the clinicians.

\subsubsection{User research for design}

The very early stages of conceiving new products are often called the Fuzzy Front End (FFE) of the New Product Development (NPD) process. The overall goal of this phase is to determine what is to be designed (Kim and Wilemon, 2002; Koen et al., 2001). Research is conducted to capture design insights, which are framed into product directions. Then, the design process is initiated. This thesis is concerned with this specific FFE phase which generates the knowledge to justify and inform the design process.

One relevant activity in these early definition stages is user research. Design research functions as a "spring board for the designer's creativity and values" (Laurel cited in Saffer, 2010). Futon Suri, in her role as Chief Creative Officer at IDEO, (2008) emphasizes that design research activity does not rely purely on analytic methods but also draws from intuition and 
interpretation to imagine and empathize with users. In her view, design research for New Product Development (NPD) is a key activity for radical innovation involving both evidence and intuition "evidence to become informed and intuition to inspire us in imagining and creating new and better possibilities". She further explains:

How can you find out what is going to matter to people if it doesn't yet exist? And this new thing that you might develop (but that doesn't yet exist) - how do you discover what kind of people it might appeal to? [...] effective research is not just about analysis of objective evidence... it's also about the synthesis of evidence, recognition of emergent patterns, empathic connection to people's motivations and behaviours, exploration of analogies and extreme cases, and intuitive interpretation of information and impressions from multiple sources. This type of approach is now often referred to as 'design research' to differentiate it from purely analytic methods. At its core, design research is about informing our intuition (Suri, 2008, p. 54).

However, many new product developers tend to rely heavily on their intuition and little on evidence. The practice of design is often regarded as the act of generating solutions and not also as a problem identification activity. Laurel notes that "many designers still believe that they 'just know' what will work for their audiences "(p. 77). This is a problem because they make assumptions of their audiences' needs, and therefore, the products they develop are less likely to succeed. She continues suggesting that as a designer one needs to "deliberately identify biases and beliefs about a subject of study and to 'hang them out the door' so as to avoid selffulfilling prophecies. One must then frame the research question and carefully identify the audiences, context and research methods that are most likely to yield actionable results... often the success of a research program hangs upon how the question is framed." Figuring out ways in which designers can suppress their individual ideas of the future and their own experiences to focus on understanding the users within complex contexts such as healthcare remains an important focus of study.

This thesis follows the principles of user-centered design approaches thereby attempting to uncover the needs of a particular team of mixed professionals working toward a common goal. It falls into the user research activities that take place in the FFE of NPD, which attempts to 
define the problem space via a focus on achieving an empathic connection with professional behaviors and motivations.

\subsubsection{Design methods and techniques for health design}

There has been an increased interest in the design literature to define and develop research methods to systematically define the context, problem space and people to design for, and based on this information, to select the most appropriate research methods, analysis approaches and ways to synthesize the information (Cross, 2007; Jones, 1992; Schön, 1984). Several authors in the field of Human-Computer Interaction and information technology provide insights on techniques to conduct user research and frame design findings (Saffer, 2010; Beyer \& Holtzblatt, 1998; Cooper, 2007; Norman; 1988).

Ethnographic-based field study techniques are used to understand a culture other than that of the researcher (Wilcox, 2005). In this view, the potential design context is regarded as a new culture. These techniques work under the principle that by observing the natural habitat, the designer can gain valuable insights about what is needed.

Methods such as Goal-Directed Design (Cooper, 2007) and Contextual Design (CD) (Beyer \& Holtzblatt, 1998), have emerged to guide the design process of software products in particular. These two methods utilize various techniques to understand the users and their domain, to model the roles and the context use, to generate requirements, to define system functions and the structure of the overall user experience. Underlying the goal-directed approach to design is the premise designers must truly understand the goals of a user, both personal and objective, in order to solve the problem in the best possible way. This is so that product balances business and engineering concerns with user concerns. Cooper's goal-directed design process is divided into six phases as depicted in figure 4: research, modeling, requirements framework, refinement and support. His work emphasizes the importance of modeling user behaviors. 


$\begin{array}{llllll}\text { Research } & \text { Modeling } & \text { Requirements } & \text { Framework } & \text { Refinement } & \text { Support } \\ \text { users } & \text { users } & \text { definition of user, } & \text { definition of } & \text { of behaviors, development } \\ \text { and the } & \text { and use } & \text { business, and } & \text { design structure form, and } & \text { needs } \\ \text { domain } & \text { context } & \text { technical needs } & \text { and flow } & \text { content }\end{array}$

Figure 4. The Goal-Directed Design process (Cooper, 2007)

Contextual Design is also a user-oriented method for the design of information systems (Beyer and Holzblatt, 1998). Here too, there is an inquiry phase that combines observations and interviews as a way to gain an understanding of a given practice. Employing these two ethnographic field study techniques helps to construct a rich picture of the work situation that reveals the roles, responsibilities and existing tools. The rationale for talking with the user during the performance of the tasks is that it deepens the understanding of why and how the subject does what he or she does. In this way it helps the researchers to identify the goals of the user and the perceptions of the extent to which the tools support their work. Artifacts used to perform those tasks are also drawn from observations and notes are taken regarding the disturbances or distractions caused by these artifacts (Löwgren and Stolterman, 2004). After the inquiry is completed there is an interpretation phase when the design team comes together to discuss each user's descriptions and insights. Here the data are organized and modeled.

In order to organize qualitative data gathered through interviews and observations, the design research team creates affinity diagrams (Beyer and Holtzblatt, 1998; Kolko, 2011). An affinity diagram is a visual tool that is created by recording separate ideas on individual cards. These cards are spread out on a surface and moved around to find related ideas and create groups out of them. These groups can be again clustered to reflect a hierarchy among the groups of ideas. This is a helpful bottom-up tool for identifying emergent patterns. In addition, in order to represent the work practice, the research team uses some or all of five different types of work models as relevant to the project focus. As described by the CD authors these are (1998, p. 86):

- flow, representing the communication and coordination necessary to do the work,

- sequence, showing the detailed work steps necessary to achieve an intent:

- artifacts, showing the physical things created to support the work, along with their structure, usage, and intent,

- cultural, representing constraints on the work and 
- physical showing the physical structure of the work environment as it affects the work.

A consolidation phase follows to bring all insights together. Separate models for each user are compared to generate a unified model that represents the whole process. An affinity diagram identifying the common issues, worries and key elements of the practice is also built. These steps provide the design research teams with the data that "can support the chain of reasoning to move from data to design" (1998, pp 86). One disadvantage of this method is that it is time consuming. Because it is intended for design research teams, the construction of the models and the categorization of the data at those levels are difficult for one person to do. I planned to create flow, sequence and artifact models to describe the process and affinity diagrams to analyze the most relevant issues.

Contextual Design has been applied to describe work practices with the intention of informing the design of new information technologies. A case in point is the dental care study titled $A$ preliminary model of work during initial examination and treatment planning appointments (Irwin et al, 2009), which uses contextual design to identify the roles of various users, the tasks and goals associated with each user as well as the information flow in the process of assessing and treatment planning of dental cases. The authors used a combination of observations and interviews to piece together the major activities, and, more importantly, to identify workarounds and 'pain points' the various actors experience in their daily practice. Another study used contextual inquiry to study the information needs of clinicians in ambulatory care (Tang et al, 1995). This study consisted of an inventory of clinical technology, a survey, observations and interviews. Here too, the combination of the various data collection instruments allowed the researchers to attain a broad picture of the workplace and identify potential 'gaps' that offer opportunities for improvement.

Similar to affinity diagramming, but more rigorous, is the grounded theory approach. Grounded theory is a systematic approach to qualitative data analysis aiming at the discovery of a theory (Rogers, Sharp and Preece, 2011). In this method, the researcher codes and creates categories which lead to further inquiry. This cycle of data collection and analysis continues until no new insights emerge and a theory is developed and confirmed. Thus, in this approach the researcher does not enter the inquiry with a hypothesis concerning what the result could be (Creswell, 
2007). Data is analyzed through open coding, axial coding or selective coding. Open coding is the process of coding data piece by piece and defining categories, their properties and dimensions. Axial coding is the process of defining the hierarchy of categories and subcategories. Selective coding is the process of integrating all categories to form a theory. In the early stages of new product development, the researcher does not necessarily seek to come up with a theory but rather a rich description of a given context; therefore, the grounded theory approach is only partially used in the data analysis of this thesis. Open coding was intended for identifying emergent categories. Affinity diagramming was expected to assist in the organization of those categories into meaningful themes of issues and opportunities for design.

This thesis draws from these two methods: contextual design and grounded theory. It centers on the first steps in Cooper's model: research, modeling and requirements. It attempts to generate a rich picture of the work process of the health professionals. These methods help in the systematic analysis of the data to produce structured findings of the design insights.

\subsubsection{Methods used in healthcare user research}

Applying ethnographic-based techniques in the clinical setting can be difficult. It is not always easy to conduct observational studies due to concerns about patient confidentiality, infection control, risks to patient safety, as well as discussion of sensitive issues during consultation (Crabtree et al. 2004). Given these constraints, an alternative to observations is to conduct insitu' interviews. These types of interviews take place in the work setting but not while the user is performing the task. The advantage of interviewing 'in-situ' is that the environment provides a wealth of information to the researcher about objects and procedures that interviewees may forget about when interviews are conducted away from the workplace (Wilcox, 2005; Bødker, Kensing and Simonsen, 2004). They, therefore, allow interviewees to demonstrate specific tools, such as files, computer systems, and so forth which enrich their descriptions. This form of interviewing also entails less time and hassle for the interviewee as it eliminates the need to commute to other places.

Interviews may range from highly structured to unstructured. Structured interviews follow very precisely worded questions with pre-fixed response options, while unstructured interviews ask broader questions that are looking to elaborated answers (Bødker, Kensing and 
Simonsen, 2004). A semi-structured combines features of the two, often asking about 10 questions to maintain the focus but allowing the participant to expand on their answers. They can also be 'open', that is to say that the researcher can ask questions during the interview to create a form of dialogue. Open semi-structured interviews were used in this investigation.

All documents and artifacts observed and collected from participants during in-situ interviews are valuable for building a full representation of the work process. As described by Bødker, Kensing and Simonsen, (2004) document analysis involves reading and scrutinizing the content of relevant documents. There are three types of analysis that can be done: initiation, in-line and in-depth. The initiation phase analysis helps gain an overall understanding of the setting under study. The type of documents typically used here includes annual reports, presentations, and organizational diagrams. An in-line analysis looks at descriptions of projects that relate to the design research project. Finally an in-depth analysis phase involves analysis of work descriptions, manuals, and forms used in the work domain. The details from these documents often support the insights established during interviews. Hence, in order to understand the way professionals communicate and their information needs in the present case study, an in-depth document analysis of evaluative forms, databases, training material as well as of institutional manuals and reports was to be performed.

\subsubsection{Visual mapping}

A common tool used to model clinical process is process mapping, also known as, flow charting. Process maps show the high-level stages of a service and its discrete steps. It is a tool that originated in business practices. It is one of the various tools provided by Health Quality Ontario, an independent government agency, to guide health institutions in quality improvement by identifying and eliminating duplicate steps and needless processes (HealthQualityOntario, 2012). Process mapping can be done at different levels of detail. The high-level is the most basic and lists the main steps in a process as shown in figure 5. 




Figure 5. Example of a high-level process map for emergency department visit $(H Q 0,2012)$

A more detailed process map is called a 'swim lane' diagram, because it resembles the way lanes divide the swimming areas in a pool figure 6. In this type of map, each individual role that is involved in a shared process is assigned a 'lane', that is, a row or a column. Then, the steps taken by each member in relation to the high-level process are plotted.



Figure 6. Example of a swim lane process map for a primary care visit $(H Q 0,2012)$

From a design perspective, mapping these steps helps in identifying problem areas and figuring out where the problems and opportunities lie within the process (Saffer, 2010). Mapping techniques are gaining popularity in design in general as the increasing concern in redesigning the clinical experience demands an understanding of the 'big picture' to identify touchpoints and breakdowns within complex processes. Privitera et al (2012) used visual mapping 
techniques in combination with ethnography to map clinical procedures for design teams to uncover "those aspects of a procedure or a device that should be changed based on preferences and those that must be addressed in order for the practice to advance." (p. 232). The authors found that mapping assures clear communication of research findings across various disciplines and confirms design interpretations with users. Alternatively, these maps served as a training tool for novice product users. In the present case study, visual mapping techniques were planned to be used for representing the interpretations of the professional's descriptions, and were expected to facilitate the verification with clinicians.

The preceding section reviewed approaches methods and techniques of exploring design requirements of user groups in the healthcare setting. The methods of inquiry used recommended for this type of user research investigation are of a qualitative nature and include a mix of interviews, observations and artifacts analysis that help construct a 'picture' of the current practice. In clinical settings, conditions in which this type of design research is conducted may vary; consequently, research methods must be adapted to the specific constraints faced during the investigation.

This case study focused on the three initial phases of Goal-Directed Design which are: Research, Modeling, and Requirements, to investigate a particular group of people with particular goals, working in a certain environment. The objective was to discover the latent needs that lie within these people's daily routines.

F or data collection the present case study intended to follow contextual inquiry techniques using in-situ semi-structured interviews and gathering materials from participants. For data analysis, it was intended to take a grounded theory approach to coding the data and identify themes of common issues and patterns of behavior. It was expected that these data could be modeled in the form of maps and scenarios with the main purpose of verifying the interpretations and locating the issues within the process. These methods were expected to provide a systematic way to analyze the data and produce structured design insights. 


\subsection{Summary of literature review}

This is a short summary of the key findings that emerged from exploring the literature concerning the rehabilitation care practice, the tools and technologies associated with workflows in this area and the approaches and methods used in the conceptualization health products. These findings frame the decisions made regarding the methodology of the present study.

In summary, the literature review revealed that as models of care continue to evolve, there is an increasing need for designers and developers to understand the new requirements that an integrated collaborative practice brings for new products. To date little has been documented concerning the needs of a group of professionals from various disciplinary backgrounds collaborating to provide rehabilitation care. This information is critical for new product developers.

Although some applications of these methods were found in the health technology development literature, no evidence was found of applications in the field of rehabilitation care. No examples of process mapping of integrated collaborative care were found for assessing the needs of various professionals with interdependent roles.

Hence, through a descriptive case study of an interprofessional team at the Elizabeth Bruyère Hospital geriatric rehabilitation unit, this study seeks an understanding of the IPC practices and the needs of four professions involved in the rehabilitation care of patients with hip surgery. 


\subsection{METHOD}

\subsection{Participants}

The case study comprised two phases of semi-structured interviews. Phase I was an inquiry phase and phase II was a verification phase. A sample of nine healthcare professionals with experience in geriatric rehabilitation took part in this study. All were recruited via personal contacts and by recommendation of personnel in different hospitals in Ottawa (see Appendix A for the recruitment notices). The sample comprised three physiotherapists, three occupational therapists, two nurses and one physician, eight of whom took part in phase I labeled I in Table 3 below). Phase II interviews (labeled II in Table 3) were held with participants who were able to make themselves available $(n=5)$. All but one of the latter took part in both interviews. Phase I interviews were conducted individually in sessions lasting between 35 and 45 minutes, while all phase II interviews lasted between 25 and 30 minutes. Participants volunteered their time and were given a $\$ 10$ Starbucks gift card in appreciation of their participation. Interviews were arranged to take place at the participant's workplace. One interview was held at Carleton University and the rest were held in three different hospitals in Ottawa. All of the interviews were conducted in a conference room or office setting, except for one, which was held at the hospital mockup kitchen which is normally used for assessments. 


\begin{tabular}{lll} 
Profession & Institution & Phase I / Phase II \\
\hline Physician & Elizabeth Bruyère Hospital & I \\
Physiotherapist 1 & Elizabeth Bruyère Hospital & I \& Il \\
Physiotherapist 2 & Elizabeth Bruyère Hospital & I \& II \\
Physiotherapist 3 & Riverside Hospital & I \\
Occupational Therapist 1 & Elizabeth Bruyère Hospital & I \& II \\
Occupational Therapist 2 & Ottawa Rehabilitation Centre & I \\
Occupational Therapist 3 & Ottawa General Hospital & I \\
Nurse 1 & Elizabeth Bruyère Hospital & I \& II \\
Nurse 2 & Elizabeth Bruyère Hospital & II
\end{tabular}

Table 3: Professions and number of participants in the study

\subsection{Materials and Apparatus}

Recruitment email scripts prepared for each type of professional were used in phase l, with another set of recruitment email scripts written to invite participants to take part in phase II (see Appendix B). Carleton's Connect account was used to manage the emails. All emails were downloaded from the mail servers upon receipt and stored in a personal external hard drive.

Two interview protocols were prepared, one for each phase. Further questions were added to the first protocol for those interviewees who had some knowledge of assistive technologies (see Appendix C). Introductory scripts and debriefing forms describing the purpose and details of the study were also used in the interviews (see Appendix D). Informed consent forms were also used (see Appendix E \&F).

A password-secured blog was created in WordPress, hosted on a safe server at Carleton University, to enable participants to access content materials and share comments (see Appendix $\mathrm{G}$ for email instructions). Materials used during the verification interviews included a video and a model in PDF format. These were available in digital form on the blog and in a printed version. NVivo 9, residing on a university's laptop computer, was used for coding and manipulating data. A digital voice recorder was used to record every interview. An iPad was used during verification interviews to show a video. 


\subsection{Design}

First, phase I interviews and archival data collection were completed simultaneously, followed by data analysis $I$. Then the data was synthesized in the form of visual materials. These visual materials were subsequently used as a basis for the phase II interviews. Next, artifact analysis was performed followed by verification interviews. All data was consolidated in data analysis II. Design synthesis was done to illustrate the findings. The design is outlined in Figure 7 below.

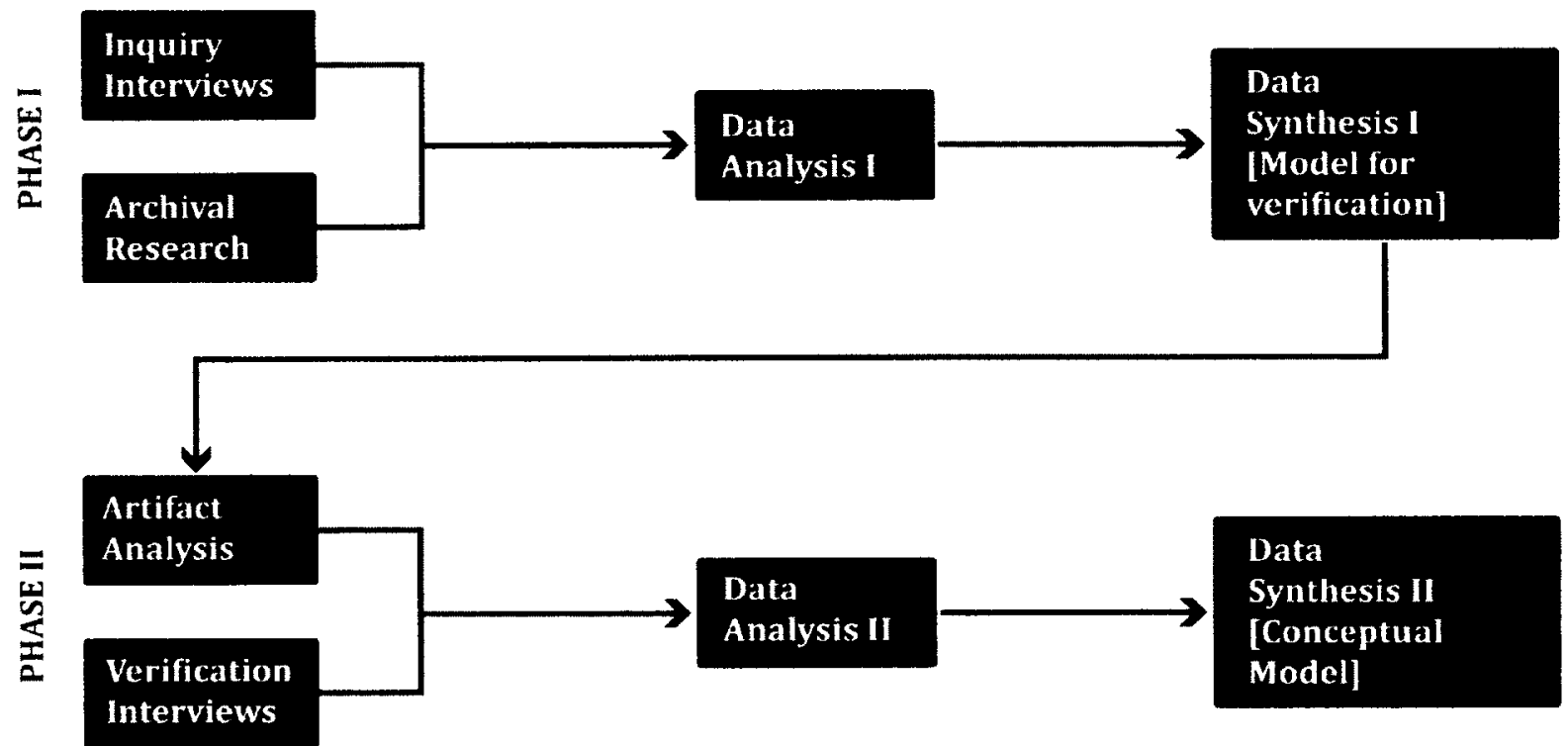

Figure 7: Study design

\subsection{Procedure}

Phase 1 interviews:

On the day of the inquiry interview, the researcher introduced herself and presented the participant with the informed consent form to be read and signed. The researcher began the session following the semi-structured interview script (Appendix $\mathrm{H}$ ). A brief explanation of the purpose of the study was given and permission to record the session was requested. Then the researcher proceeded to ask questions. Once finished with the questions, the researcher provided an opportunity to ask questions and give further comments. The researcher requested permission to obtain a copy of the forms and materials referred to in the conversation. Then the 
participant was debriefed and asked if contact at a later time was possible in case clarification was required. A coffee shop gift card was given to the participants in show of appreciation for their time.

Phase II interviews:

On the day of the verification interview the researcher greeted and presented the participant with the informed consent form to be read and signed. The researcher began the session following the structured interview script (Appendix L). Those participants who said that they had not watched the video or looked at the diagram were walked through them on the iPad. Then the researcher proceeded to ask questions. Once the video had been discussed, the researcher showed the diagram and began asking questions. During the conversation, participants were encouraged to write on the diagram to explain where changes were needed. While discussing these changes, the researcher continuously probed for issues commonly faced in the process and weaknesses of the tools. The last portion of the interview invited participants to think about what the ideal way would be to carry out those tasks that seemed problematic. They were given three statements describing design ideas to address some of the issues identified in the first round of interviews. Once finished with the questions, the researcher provided the opportunity for the professionals to ask questions and to show tools that were not accessible during the session. Then the participant was debriefed and invited to visit and leave any new comments or ideas in the blog. Upon completion of the interview, the researcher thanked the participants and gave a coffee shop gift card in show of appreciation for their time.

\section{Collecting clinical artifacts:}

In the email invitation participants were asked to bring to the interview all materials or tools they use to carry out their daily tasks including forms, protocols. The researcher coded them by profession for later analysis.

Archival data:

Online searches were made to obtain institutional documents mentioned by the professionals. Documents, forms, reports, protocols and policies were collected from the Ontario Ministry of Health, the Elizabeth Bruyère Hospital and the CIHI websites and online publications. 


\subsection{Qualitative data analysis}

Phase I interviews:

Audio recordings from the inquiry interviews were transcribed verbatim and loaded into NVivo 9 to facilitate the coding process. A content analysis was done through open coding to organize and label the data into twelve themes and issues around the aspects elicited in the initial interview questions, including: roles, data used in assessments, tools, issues, procedures, timeframes, and admission criteria. After each interview, the researcher wrote a memo reflecting on what was learned from that interview. Each memo contained the interviewer's impressions about the participants' experiences, and the interviewer's reactions. In these memos, comparisons were made between data in order to find similarities and differences, which in turn raised questions to be answered in continuing interviews. During coding, a journal was also created in Nvivo 9 to record thoughts about the meaning of codes and about how and when processes occurred.

Affinity diagramming followed coding to organize the individual notes captured during the sessions into a hierarchy revealing common issues and themes. Next, process mapping techniques were used to analyze the sequence of tasks involved in the process, the intent behind each task and the role of each professional. Finally, all the forms collected from participants were matched to the tasks to understand in detail the type of information used in the process.

During data collection and analysis the researcher developed a tentative process model of assessing, treating and discharging a patient, from the perspective of physicians, nurses, physiotherapists and occupational therapists. This was expressed in the form of a video and a visual. The video was a storyboard consisting of 16 hand drawn images that were assembled together using Windows Movie Maker. A voice-over was recorded for the narrative of each image. The visual was a model inspired by various task-mapping and process-mapping techniques. It was created using Adobe Illustrator.

Phase II Interviews:

During the verification interviews notes were taken and the times in the audio recording when the participant provided new or additional information were marked. These sections were 
transcribed and analyzed through open coding to organize and label the data into themes. In this phase, the content analysis was done by printing the notes for each participant, colour coding them with marker, cutting them and sorting them by hand. This allowed the researcher to add new information to the affinity diagram created in phase 1 , and to continue the comparison of data. A consolidated affinity diagram including description of the work process and related issues was created.

Artifact analysis:

A systematic artifact analysis was conducted to corroborate findings from the interviews and complement the data gathered through interviews. All forms, protocols and artifacts mentioned and gathered were listed and categorized by profession. Content analysis was performed to understand information needs and flow in relation to the team activities identified.

DATA ANALYSIS I



Inquiry Interviews $\&$ Archival Research

Verbatim transcripts \& coding

Affinity diagramming

Process mapping

Storyboard video Workflow model
DATA ANALYSIS II

Artifact Analysis \& Verification Interviews

Interview notes $\&$ coding

Consolidated affinity diagram

Revised process map Content analysis

Conceptual model

Figure 8: Qualitative data analysis process 
Figure 8 details the techniques used to analyze data and synthesize findings. These correspond to the boxes 'Data analysis I' and 'Data analysis II' in figure 7. The dark gray boxes present the sequence of steps taken in the process. The light gray boxes represent the two main rounds of data analysis.

The description and interpretation of the findings resulting from the three methods chosen and detailed in this chapter: interviews, artifact analysis and archival research, are presented in the next chapter of this thesis. 


\subsection{RESULTS}

An analysis of the data yielded from the interviews, artifacts and archival data revealed answers to the research questions. Professionals' interview responses were first grouped by profession to correspond to the research questions and then categorized for major themes or patterns. The results under each research question are presented by instrument of data collection.

\subsection{Research question one: What are the main tasks and goals of the team workflow?}

Inquiry interviews and archival reports were analyzed to answer this question. First the responses for the various interview questions that helped answer this research question are discussed followed by the findings from archival data analysis.

\section{Key findings from inquiry interviews:}

Professionals were asked about their role and the main procedures performed with a post-hip surgery patient. A high-level process map resulted from analyzing professionals' descriptions of the standard tasks and goals involved in the process from admission to discharge. Instances describing important tasks of each role were grouped by profession and then organized chronologically in order to determine the individual workflows as shown in Table 4.

Tasks

"so the first thing that we do when they come here, the PT with
the OT, we are the first people, pretty much that go and see
them to see what is their mobility status..." P3
"Primary function on day one is for the physio, OT and nurse
to do an interprofessional mobility assessment, where we
consider how safe the patient is to mobilize in our hospital
environment, what kind of equipment they need...how much
help they need to get in and out of bed, in their room" P4

"so the first thing that we do when they come here, the PT with the OT, we are the first people, pretty much that go and see (2tatus..." P3

\section{Goals}

Determine needs: people, equipment and space



Table 4. Sample of coding of instances of tasks and goals description 
Then, the resulting four workflows were compared against each other to determine the collective tasks and the associated goals intended with each task in the team process. Figure 9 shows the comparative analysis. Colours were used to code each profession, and light gray was used to show tasks done collectively. The darker gray bar along the right side of chart displays the common team goals identified from this analysis.

A total of nine common team goals were identified as part of the iterative process of assessment, treatment and discharge planning of a post-hip surgery patient, which lasts an average of 4 to 5 weeks. These goals are: determine needs in unit, develop disciplinary treatment plan, discuss status to set interdisciplinary goals, provide one-on-one interventions, reassess progress against goals, set discharge date and prepare plan, test discharge plan, confirm discharge decisions, discharge patient.

A swim lane process map of the workflow was created. Recall that, in a swim lane map, each member of the work team is plotted separately. The patient is represented along the right side, side by side to the three professionals in the team. To help understand the unique contributions and responsibilities of each role in the process and how the roles are interconnected with each other the entire process was mapped out in detail. Figure 10, presents the swim lane map.

\section{Individual vs collective work}

This analysis revealed that the majority of assessments are performed individually except for the admission assessment which is performed by a physiotherapist, an occupational therapist and a nurse. Assessments are continuously performed, some integrating these three disciplines and some separately. The results of these assessments inform the team's decision making. Discharge decisions are made collectively at weekly rounds. Discharge planning starts at admission with an understanding of patient's desires and goals and intensifies as the patient goes through the process. 

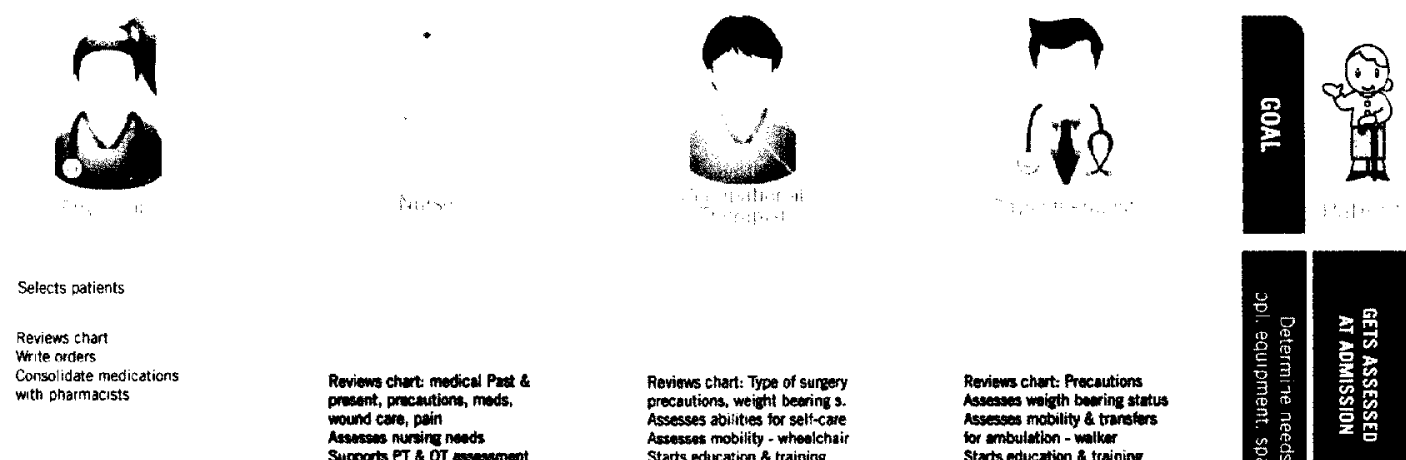

Reviews chart: Type of sungery procultions, weight betring 3. Assesses ablitues tor sellicare Assesses motity - whicentir Starts education \& training Supports PT $10 \mathrm{OT}$ monemont

Conducts in-depth or

Assecsoment (first 72has Kappe track of cara needs: trites on skin, pain, nutsition ove of exsistence for mosility 4t transters in AOL, cognition

Calcuides FIM scoess (NRS) Determine optimai leve based on prior status \& goals

Completes care plan

assessment: (pest \& present) Cognition MOCA, productivity IIADL) \& leisure available support, home setting

Calculazes FIV scores Analyzes patient's goais Hestyle independence

Wites notes $1 \mathrm{n}$ charl

Fils out fiow sheet $\&$ GRASP

Folthw up on: Dr orders

Fills sut tintervention sheets

Whes whedchair prascr: p:

Peors to other poffecsionas

Meets with team Sets teami gozis

Meets with team

Discusses progess

discharge date \& tocation

Discuss óscharze conditions

Meets with team

Sets teamn goals

Discusses discnarge location

8 equipment requiremerts

Records Interdisciplinany Care

Plan new goals

Curius out intervention:



Follows up with medical

issues
Talks to patient

Talks to patient

aspects: physical, medica

cogritive, psychosocial

Maintien winduremce of

motivation

Carries out intervention: Meets with Rehso Assistant Reassecses ADL, IDAL.

sittire assessment

Rossesess woind healine perticipution, memery

Arranges sther required mood, satty concerms

Reters to sult-medication

Investigates enviroment:

physical home. equipment

culturat: conmunity

involvernent, role expectations

ADL, IADL reassessment

Conducts home is ktichen

ansesstertis

Coordinates home services

\& equipmen:

Shares thome \& kitchen

assessment findings

Dec ides destunatior \& date

Discussas safety concerns

Sugzests destination \&
Calculates FIM scores

Discuases meds, mood

sisatety concerns

Canties out tamily conference

Sets up for eekend pass

Reviews chart: Precoutions

asseseses wigeth bewing status

of ambulation - onther

starts education 2 trainin

Taiks ebout petion'ts goats

Conducts in-depth Ptyssio

subjective findines

mability and transler PFMP balance strength, pain, ROM,

comprehension, stains

Calculates FIM scores (CAIHI) Evaluates patient's goals reasibulity: pnysical

Sots Physio zcais

\section{Writes notes in chan \\ Posts pictog a ans \\ Assigns Rehat: assistant}

Meets with team

ysia finding

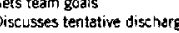

date

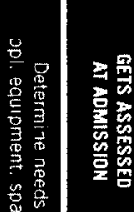

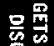

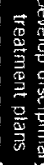

Discussess questionnaire -
feedback from trekend pass

Crries out intervention exertise program
Whiks with Rehab Assistan Resussesses mobility \& weint transfer.

mornory, dual - talak environment updates level of asssistance

Reassesses for sischarge

Arranges assistive dev ces

Plans pnst-rehab care

Carries cut a family day

Carries cut femily conference

Gives recommandations on treel of support required Teaches safe practioes: cer

Revisits discharge decisions in a्ll aspects: location

equiprrent, services
Discusscs conter as

Gives recommendations on

ve recommendations on

follow uf care

Coydinates cay hospitai io

Confirms tollow in
apposintment with Gf

Goes over mesticution list Hands ourt discharse mopor

Proviess equipment \&

instruction:

Provides discharge summary

\& walker

Gives pamphlets with

S gnis Discharge Approval

Figure 9. Comparative analysis of four professional workflows illustrating the identified team goals (dark bar) 




Figure 10. Swim lane process map displaying the unique contributions of each professional and the transitions of service from admission to discharge. 
Interdependency of roles: physiotherapy, occupational therapy and nursing

Physiotherapy, occupational therapy and nursing tasks were found to be highly interdependent; for example, the nursing assessment is informed by the physiotherapy and occupational therapy assessments. In the first 72 hours, these three professionals conduct a combined mobility assessment, in which similar criteria are evaluated, yet each professional looks at it from a different point of view. For example, tasks performed by each professional share common concerns to understand the patient's history, his or her current condition and restrictions, as well as to determine the patient's goals and environmental information. While the physiotherapist is looking to measure the ability to ambulate and transfer, the occupational therapist is mainly concerned with how mobility affects the performance of Activities of Daily Living, and the nurse is looking at the level of assistance required, as well as the overall medical concerns.

\section{Patient and family role}

The professionals emphasized that the patient and their family play a big role in the process. They further explained what they do to ensure that the patient is at the center of the treatment. The patient's goals and consent in decisions are drivers for the goal-setting process. Also, their family, when available, is invited to participate in assessments. Family conferences are onehour sessions in which the team and the future caregiver discuss discharge issues and concerns. Family day is a one-day-hands-on session in which the caregiver is walked through the care process. However, the professionals' time constraints limit the possibilities in preparing the families for the patient's discharge. It was mentioned that family days and conferences are only conducted for complex cases only.

\section{Physical environment}

The professionals performed activities in a variety of environments that included the patient bedside, the gym, training rooms and meeting rooms. Additionally, nurses provided constant support to patients in hallways and dining areas.

\section{Key findings from archival data}

The documents and reports collected were analyzed with a view to further understanding the practices mentioned in the interviews. The analysis of provincial reports and the hospital's 
protocols revealed two prominent aspects driving this team's practice; patient-centeredness and interprofessional decision-making. These two models are prevalent in the institutions in the province, in particular to those dealing with geriatric populations.

\section{Patient-centeredness}

This approach focuses on involving the patient's views in the decision making process and is intended to support the patient's efforts to become healthier with faster access and stronger links, to family healthcare. This team used the patient's goals and preferences as an important piece of information in the discharge planning process.

\section{Interprofessional Care (IPC) Model}

One of the reports illustrates the hospital's efforts in developing and implementing an IPC model of care since 2008. Under this model, a professional team performs integrated assessments and treatment, care planning and goals setting is patient-centered and shares decision making regarding the plan of care of individual patients. Figure 11 shows a summary of the guidelines underlying the new practice. It was evident that the team has generally adopted these practices.

\section{The 12 Bruyere Interprofessional Care Guidelines}

1. Each unit will "design" its version of the IPC based on:

a. Holistic, humanistic, relationship-based, and inspired care

b. Respecting the scopes of practice, maximizing peoples resources by levering "synergy"

2. The re-design of care practice will be done by team members themselves.

3. Decision-making regarding the plan of care of individual patients will be shared among all the teams' health professionals

4. The care plan will reflect integrated assessments, interventions, discharge planning and outcome evaluations

5. Care planning and goal setting will be patient-centered and this will be documented

6. On-going communications among the health caregivers of each patient will be effective

7. Double accountability: individual members' accountability to their professional standards and joint accountability by the team regarding goal attainment.

8. Mechanisms in place to support team self-assessment of effectiveness and improvement planning

9. Mechanism supporting on-going professional development and continued improvement in collaborative inter-professional practice

10. Innovative clinical practices will be valued and encouraged as part of a context responsive approach to care delivery

11. Patients/families will have continuity of care: same care providers (as possible), improved charting, and improved inter-shift communication

12. Trainees in all disciplines will learn the IPC approach

Figure 11. The 12 Bruyère Interprofessional Care Guidelines (Bruyère Continuing Care, 2010). 
In sum, the preceding section revealed findings regarding the general protocols and procedures involved in the process from admission to discharge of a patient in post-hip geriatric rehabilitation. It revealed details of a team workflow that consisted of nine goals with their associated tasks. The findings demonstrated individual and collective tasks, and the existence of interdependent roles particularly, among physiotherapy, occupational therapy and nursing. The findings also show a patient-centered practice.

\subsection{Research Question Two: What are the current tools that support the workflow?}

Inquiry interview responses were grouped by professions and analyzed to correspond to this research question then categorized for themes. These findings are presented first followed by the analysis of the artifacts collected during interviews. A description of the main tools used in the practice is provided together with details on the teams' information needs and some of the issues related to presentation and structure of information in the existent forms.

\section{Key findings from inquiry interviews:}

All tools mentioned by the professionals were listed first. From this list the tools that supported the achievement of the nine goals of the team's workflow were identified.

The analysis of interview responses revealed that the most common tools used by the team are used for information management and communication purposes. A combination of paper-based forms and digital databases were used to manage patient information. The patient chart and a bedside board were used to support communication of such data. Comments on the usage, issues and 'pain points' were captured to illustrate the professionals' opinions in supporting the workflow.

- Paper forms were the most prominent way to capture and document data overall. Some professionals commented that the multiplicity of forms used to document each patient at every session takes up almost one third of a workday.

- A total of three databases were mentioned, however the Functional Independence Measure (FIM) was the only database used collectively. It was considered a key tool for all professionals in supporting the discharge planning process. The FIM is mainly 
used by the institution to help determine the burden of care. It is composed of 18 items (13 motor items and 5 cognitive items) which are rated on a standardized 7point scale to describe the patient's level of independence of functional performance; with seven (7) being fully independent and one (1) being totally dependent. The sum of the ratings provides a total function score with a maximum of 126 (18x7) (Canadian Institute for Health Information (CIHI), 2007). The scale was used as a common quick way to communicate patient status, for example, saying a patient is FIM 5 was enough for everyone to know the level of assistance the patient would still need.

- The patient paper chart plays a very important role in team communication as it stores all patient-related information in one binder. Here too, there are limitations in terms of retrieving information, sharing updates and documenting simultaneously with other team members.

- The bedside bulletin board was mentioned as the main place to communicate the basic requirements for safe mobility of a patient. It is used to post iconic representations of the required assistance for mobility called 'pictograms' Figure 12. These play an important role in advising the required assistance for safe mobility at all times. The board is also used to write notes on the assistance currently required, precautions and restrictions for the patient. The physiotherapist is in charge of posting and updating the cards.
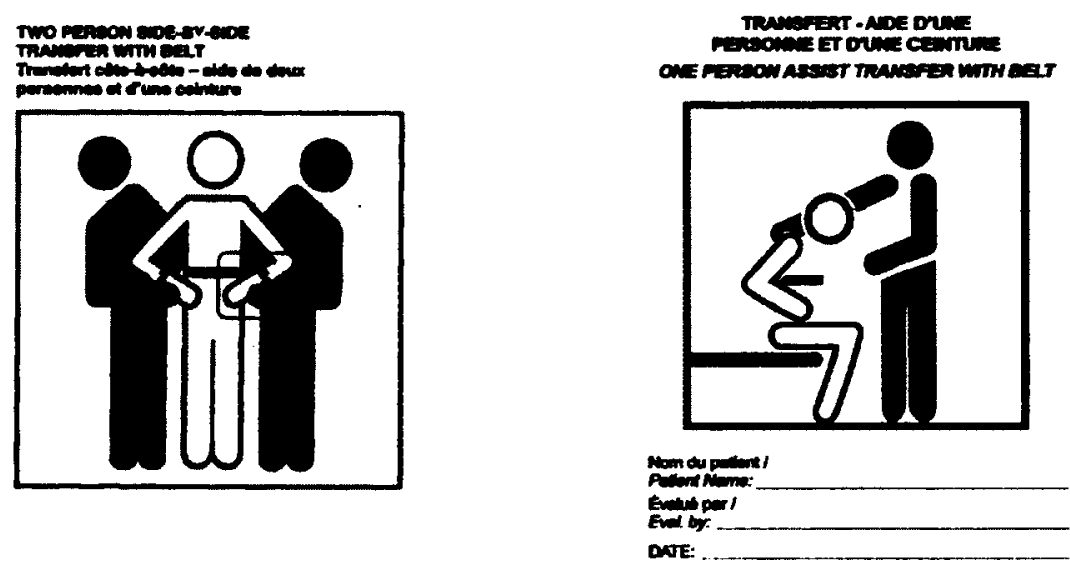

Figure 12. Sample of pictograms provided by professionals interviewed. These images are typically posted on the bedside bulletin board to indicate patient's level of assistance required (Bruyère Continuing Care). 


\section{Key findings from the artifact analysis}

Analysis of the artifacts was performed to help determine how these supported the team's intentions in the workflow. A total of 27 forms collected were grouped and analyzed. The findings are presented under two major units of analysis: the presentation and structure, and the content. Each description is followed by an interpretation of how the artifacts supported the tasks in the workflow.

\section{Artifacts Presentation and Structure: Assessment forms}

The majority of forms were used for assessment activities $(\mathrm{N}=10)$. These forms included standard outcome measures, admission summaries and hospital custom forms for each discipline. At first glance it was apparent that presentation of data and structure follows a silo disciplinary format; that is, most forms derive from each discipline. A comparison of forms used by the physiotherapist and the occupational therapist showed that each profession records the same terms several times but with different terminology and structure.

Evaluative Forms For Assessment

\begin{tabular}{|c|c|c|}
\hline $\begin{array}{l}\text { ACTIVTIES OF DAILY LVING } \\
\text { (Occupational Therapy) }\end{array}$ & $\begin{array}{c}\text { PFMP } \\
\text { (Physiotherapy) }\end{array}$ & $\begin{array}{l}\text { BERG BALANCE } \\
\text { (Physiotherapy) }\end{array}$ \\
\hline $\begin{array}{l}\text { Bed mobility/Transfers } \\
\text { Roll side to side } \\
\text { Bridging } \\
\text { Sit up } \\
\text { Lie down } \\
\text { Sit unsupported } \\
\text { Come to standing } \\
\text { Turn } \\
\text { Sit down } \\
\text { Safety aspects } \\
\text { To/From bed } \\
\text { Wheelchair - chair } \\
\text { Toilet } \\
\text { Tub-Shower }\end{array}$ & $\begin{array}{l}\text { Bed Mobility } \\
\text { Rolling } \\
\text { Bridging } \\
\text { Lie/Sit } \\
\text { At side of bed } \\
\text { Sitting Balance } \\
\text { Feet unsupported } \\
\text { Side of bed } \\
\text { Sit/Stand } \\
\text { Standing Balance } \\
\text { Transfer } \\
\text { Bed, chair, wheelchair, toilet } \\
\text { Wheelchair locomotion } \\
\text { Indoors, manual, electric } \\
\text { Ambulation } \\
\text { Indoors } \\
\text { Stairs } \\
\text { 12-14 indoors up and down }\end{array}$ & $\begin{array}{l}\text { Sit to Stand } \\
\text { Stand unsupported } \\
\text { Sitting unsupported } \\
\text { Stand to sit } \\
\text { Transfers } \\
\text { Stand unsupported } \\
\text { Reaching forward } \\
\text { Pick up object from floor } \\
\text { Turn and look behind } \\
\text { Turn } 360 \\
\text { Place feet alternately on a } 7-8 \text { inch } \\
\text { stool, no support } \\
\text { Stand unsupported, tandem } \\
\text { Stand on one leg }\end{array}$ \\
\hline
\end{tabular}

Table 5. Comparison of terminology and clustering of information in three different forms (two from physiotherapy and one from occupational therapy) showing inconsistency of data presentation and structure.

For example, although categories such as Mobility, Self-care and Transfers were present in all three disciplines, items under these categories vary. For instance, different terminology was 
used to assess the ability to stand "Come to standing" (Activities of Daily Living Assessment) "Sit/Stand" (PFMP), "Sit to Stand" (BERG Balance). Two of these forms are used by physiotherapist and one is used by the occupational therapist. The inconsistency of terminology and clustering of information as shown in Table 5, poses challenges in the management of information as it fails to support the integrated gathering and analysis processes expected under the interprofessional model of care.

Moreover, scoring scales used by each profession also vary considerably. The scales' ranges differed. For example, while occupational therapy uses a 0-4 scale to indicate level of assistance, the FIM uses a 0-7 scale. Professionals are required to recalculate to reflect the equivalent FIM scores, since these scores are not always congruent across forms, which adds time to the documentation processes. Also, inconsistent order of items in the scales was identified. While the Kardex used a scale I-SU-S- A1- A2 to indicate the level of assistance, in the Admission Health form the order of two items was flipped for no apparent reason I - S- SU- A1- A2. Furthermore, when comparing the presentation and structure between paper forms and databases these also varied even within each discipline.

Artifacts Presentation and Structure: Treatment forms

A smaller set of forms $(\mathrm{N}=5)$ were used in diagnosis and treatment formulation. These forms recorded summaries of objective and subjective findings, intervention procedures and disciplinary goals. The Interdisciplinary Integrated Plan of Care was the only paper form used interprofessionally and was the most practical way for the team to track a patient's progress. Since calculating the full FIM scores is done only at admission and discharge. The same form is updated at weekly rounds to document goal setting and attainment and to indicate the level of assistance needed in accordance with FIM scale.

\section{Artifacts Presentation and Structure: Discharge forms}

Three forms were used for discharge planning purposes. It was not clear whether all the discharge forms were used with every patient. Some professionals said that forms such as the discharge checklist and the home questionnaire were used regularly. However, other professionals explained that these forms were no longer used. One of the physiotherapists expressed concern that the checklist was no longer used and explained that this form was 
important to keep a record of the arrangements made for the patient prior to discharge, especially in the cases of a patient who has returned to in-patient care because something goes wrong.

\section{Artifacts information content:}

The professionals described the artifacts and explained their purpose so that the most relevant clinical data used by the team in discharge planning could be abstracted. The most common pieces of information mentioned by all professionals that are key in discharge planning were:

- Patient goals: what the patient wants to be able to achieve after discharge

- Functional abilities towards achieving patient goals and safe mobility: Mobility and transfers, Continence, Self-care, Cognition

- Environment and lifestyle: The patient's physical environment (house layout, assistive devices, etc) and settings of daily activities (e.i. visit the mall, church, etc)

- Available support including friends, family and community resources: the patient's available support (widow, a close-by daughter, CCAC)

These items were mainly identified through the professionals' explanations. However, documentation of these items was not clearly distinguished from the content analysis of the forms.

\section{Information needs}

An analysis of the items used by each professional was performed to determine the discrete pieces of information relevant to each profession and the intersections of these among the four professions. Description such as the one provided by one of the nurses helped in discriminating the items. The following is an example of how a nurse would write notes on the chart to report the five major aspects of her role after seeing the patient:

we have seen patient in bed, she is alert and oriented (Cognition), patient needs 'assist of 1' for in and out of bed with a two-wheel walker, she is able to walk with 'assist of 2' to the bathroom, but for long distance she needs a chair (Transfer \& Mobility). Patient is able to pull down and up her pants but needs assist to do the peri-care and she will use a pad for 
her incontinence (Toileting). She needs set up at the sink, she is able to do her upper body but needs help of assist of 1 for the lower body she is able to trench her pants with a reacher (Self-care). She is continent of bowel (Continence). The level of complaint is on 6 out of 10 (Pain). And she eats 100\% for breakfast and lunch.

Figure 13 shows a discrimination of the unique pieces of information that contribute to a collective evaluation of patient functional performance. Each professional reports assessment results to the team. The physiotherapist must report on mobility, transfers, ambulation, balance and required assistive devices. The occupational therapist reports on Activities of Daily Living (ADL) instrumental Activities of Daily Living (IADL), as they relate to the ability of patient to cope with the environment. The nurse reports on ADL as they relate to the overall health status. The physician makes the final decision accounting for all professional recommendations. All professional inputs aim at providing an evaluation of cognition, self-care, mobility transfers and ambulation. These are discussed to evaluate patient progress and set clinical goals. Patient goals are reported by all professionals as they relate to their contributions. These are taken into account in goal-setting for discharge planning.

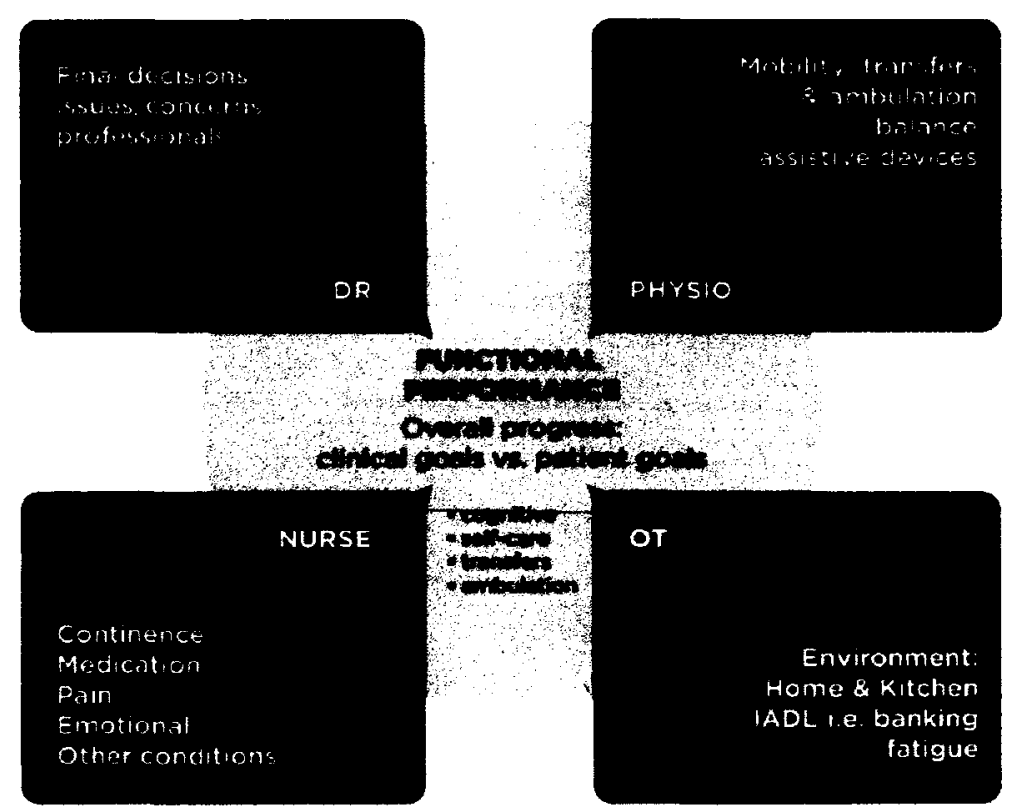

Figure 13. Each colored box represents one profession. The information inside the box is of unique concern for that profession while the information inside the circle is of collective concern to all. All professional contributions contribute to the evaluation of patient functional performance. 
From this analysis, it was evident that the nature of the task varied from professional to professional, so while the nurse would need to record data at a daily basis three shifts a day, the physiotherapist would do it two or three times during therapy sessions. The type of information also varied. While the nurse may check off or record readings on a list of items, the physiotherapist would be more interested in looking at the change of specific measures taken over time. Finally, the environment in which this data was recorded varied as well. While the nurse more often takes these readings at patient bedside, both therapists would do it at the gym or training rooms.

In essence, this section presented an interpretation of the findings identifying the current tools that support the team discharge planning process. It revealed five main types of artifacts used for information management and communication, namely, paper forms, the FIM instrument, the patient chart and the bedside bulletin board. The content analysis of the forms revealed details on professionals' information needs and demonstrates issues related to presentation and structure of information in the existent forms. Furthermore, the findings show a limited number of forms used collectively. The most relevant were the FIM and the Integrated Plan of Care which were essential in coordinating activities and supporting decisions. Communication tools were limited to weekly face-to-face meetings, as well as the annotation in the patient's chart and the bedside bulletin board.

\subsection{Research Question Three: What in the workfiow could be better supported by design?}

Responses for the inquiry and verification interviews were combined to reveal themes regarding issues, 'pain points', weaknesses and wishes in the workflow. Ideas expressing how professionals envisioned the practice were also included. Quotes were captured in individual notes and organized into a hierarchical affinity diagram to reveal common issues and themes. The insights in this section fell into four categories: data management and information sharing, decision support for mobility monitoring, decision support for discharge planning, and patient education. The issues under each category are detailed below and are ordered by the frequency of occurrence. 


\subsubsection{Insights related to data management and information sharing}

Large number and types of recording instruments

Some professionals commented that although most forms are basic and straightforward, there were too many forms to fill out. One occupational therapist showed a cabinet with more than fifty forms used in Occupational Therapy ałone!

\section{Various inconsistent formats}

All forms, reports, tests results, etc. are stored on paper with the patient's chart. However, the professionals mentioned that dealing with various formats is not very efficient because navigating through data is time consuming. Moreover, the partial implementation of Electronic Health Records has increased the time it takes for documenting a patient. As one occupational therapist explained, "when I wrote the notes by hand, I was able to take the actual form to the bedside and I'd be writing as I was talking to the patient, so I had the notes half done. Now, I am making notes and I am taking them out and redoing the notes in the computer system... I think it takes about $\mathbf{4 5}$ minutes to input an initial assessment...[which] is four pages long. It takes a bit of time to complete that form on the OACIS [Open Architecture Clinical Information System]." She then suggested that it would be better if information could be entered directly into the system at the bedside, perhaps through a portable device, and be accessible later to be analyzed, completed and published.

\section{Difficulty of retrieving information}

Issues related to the usability of existing databases were prominent in the discussion. Some professionals explained that the FIM presents challenges to keeping the richness of the information readily accessible. Each professional calculated scores independently during the disciplinary assessments. Only the scores for calculating a total FIM score are entered into the database. This makes it difficult to retrieve data associated with the score to make sense of the decision making process across all stakeholders. In elucidating this issue, one occupational therapist said, "sometimes there is no answers in there as to why [an item is given a certain score]: is it cognition, is it physical or which? This isn't necessarily reflected in that number so I still find that as an OT I have to look at that to understand more of what needs to be put in place... if I say a FIM 5 because I am thinking they need to be cued on how to safely step over the 
side of the tub and how to use the grab bar versus they are FIM 5 because they don't have a grab bar...well if I put a grab bar and it is because of cognition, it is not going to make them any safer." The need for a better way to record, store and transmit specific data associated with the FIM items became clear so that it could be easily retrieved and traced by any team member at any given time.

Learnability: complex scoring system

Another usability-related issue in the FIM database is the learnability of the scoring scale. To score a patient accurately requires practice and a high level of experience, so the professionals kept instructional guides to help them be proficient at assigning scores in given scenarios. One of the physiotherapists also said that scores may vary according to the professional's knowledge of the test, "It could be someone casual, just coming in one day to cover you, so it is harder for them because they are not familiar with the test or with doing it in the same way." Furthermore, it was pointed out that calculating the FIM scores for each patient at every round was time consuming so the full scoring was only performed at admission and discharge rounds. The fact that they had to convert scores from their evaluative forms may also contribute to this perception. These comments suggest that the database it is not easy to learn and use and therefore does not meet the need for the team to efficiently score patients.

\section{Limited to text, not flexible to sketch}

Additionally, electronic tools were found to lack flexibility inasmuch as they do not easily allow sketching or writing notes to document observations. One of the physiotherapists emphasized the use of visuals as an essential way to quickly summarize assessment results and expressed some of the limitations posed by current electronic systems. "It will be longer for me to type it [her observations], and at least on a paper form I can draw a pelvis this way, weight is shifting that way, head is over there... that is for me very valuable because that tells me a whole lot more than I can ever spend the time to write in words." This made it evident that there were limitations in the technology to fully support the ways in which different professionals record and analyze data. 


\section{No interdisciplinary data collection/access}

Lack of connectivity was an issue in terms of making data gathering and data sharing more integrated and accessible across disciplines and across institutions. Across disciplines, one physiotherapist asserts that data entry would be more efficient if the team could, "put everything together, and have easier access to all of the information, if it was more interdisciplinary ... as opposed to this." Across institutions, making data more accessible was seen as a way to save valuable time in the process of patient selection, aid in the initial understanding of a patient's condition at admission, as well as to facilitate in the transfer of information to subsequent caregivers at discharge.

\section{Non-interoperable data for decision support}

According to one respondent, current data management systems and tools lack connectivity to support the analysis of clinical information from multiple sources, functions which could greatly benefit interprofessional care practices. He explained that current information technologies, in general, are 'very primitive' and one-dimensional in gathering multiple and segregated pieces of information and processing it to convey information that is relevant and useful to the team. The professional ideal of a system is an interconnected network of mechanisms that supports a more holistic analysis of the patient status. His comment underpinned a need for interconnected data systems that allow interchanging medical data with other systems to support diagnosis and treatment.

\section{Duplication of questions to the patient in assessment}

The issue of lack of data synchronization was elucidated by comments expressing common repetition of questions to the patient and duplication in data gathering during independent assessments. In referring to the upcoming implementation of EHR in the institution one physiotherapist commented "I am hoping that a lot of duplications will be minimized, because what happens is that 1 could be asking the same questions that the occupational therapist might be asking or the nurse could be asking, so we are repeating the same." Repetition of questions to the patient suggests inefficient data entry mechanisms for integrated assessments. 


\subsubsection{Insights related to clinical decision support: monitoring moblity}

Lack of tools to measure qualitative parameters

Comments about a lack of tools to measure, integrate, analyze and visualize data to convey aspects about the process of regaining functional performance were common. When asked about the efficiency of current tools in analyzing data for treatment planning, several professionals agreed that they lacked ways of measuring the quality of the patient's functional status. Some parameters mentioned that could serve as indicators of quality included posture, stride, hand positioning, weight transfer, sequence, symmetry, tone of muscle, stability, limping, and weight bearing status. Some called it monitoring the 'subtle changes' that are not visible to the naked eye. One professional explained that tools such as the FIM and other outcome measures focus on calculating the burden of care, namely, determining how much assistance is needed, based on the ability to perform a function. However, they are unable to measure how well a patient is doing such a function. In explaining this concept, a physiotherapist said, "For example, sitting to standing, they could be getting up... but how they get up is the question; you know... the quality is important too... Do they do a good weight transfer to get up? How is their posture? All that... None of these [forms] capture that... They may be doing it beautifully to get up and they will be [scored as] independent and someone would be doing it really poorly and getting up and they are also [scored as] independent... [but] there is a difference, one [patient] is really shaky and limping and the other one is doing it with good length and nice striden ${ }^{n}$. The numerous comments regarding the lack of tools to capture the 'quality' of a patient's mobility performance emphasize a need for more comprehensive and detailed monitoring mechanisms that enhance measuring and reporting of functional status.

\section{Difficulty of monitoring risk of falling and prioritizing agenda}

From a more forward thinking view into the future, the physician envisioned integrated systems helping with prioritizing his agenda. He is looking forward to 'data fusion' when several types of data put together can help identify whether a person is more prone to falling or something is 'out of whack' so that the team can act accordingly. He commented that this would be of real added value as it would greatly support and perhaps change the way professionals manage their workload. He suggested that a triage function could help prioritize his agenda by showing "which one of my 100 patients should I see today, the one that didn't get up of his bed, 
hasn't watched his favorite show, hasn't had breakfast... That is the first I need to see. That is when we start really making a difference in clinicians' and residents' lives." This person believes that interconnected technology has a great potential to meet the needs of professionals in optimizing their workload, but more importantly, in providing comprehensive data that can better indicate the risks of falling.

No trend data to detect patterns of normal or normal variation in the rehabilitation process There is currently not enough understanding of the normal progression of rehabilitation, particularly in an aging population, from the clinical standpoint. The physician expressed the need to understand what is normal and what the thresholds for normal variation rehabilitation are. "So if normally one day takes me two seconds to get out of bed, the next day is Saturday morning, I am not rushing to work, it takes me eight seconds to get out of bed, is that bad or is that normal or not. So what is the variability that is OK before it is a concern or abnormal". This information is critical for teams in making discharge decisions. At an institutional level, this information can also help in forecasting and budget management.

\subsubsection{Insights related to clinical decision support: discharge planning}

\section{Absence of analysis tools for discharge planning}

Discharge decisions require constant consideration of the multiple factors and possibilities unique to each case. In order to achieve an inter-professional model of practice the team conducts integrated assessments and discharge planning. With time, they have become proficient at evaluating all possible options in their heads, but this 'logic' has never been modeled to represent such a decision-making process. In the physician's words, "We know what it is in our head, if you lived in a two-storey house, you have to be able to climb stairs. If you have one-storey and a spouse, you have to be able to do so and so. So we know it in our heads, but we've never actually written out a sort of logic". He further described what is envisioned, "If there was a way to input all factors and get a recommended discharge location, it might help ...or inversely, if you say, here it is what the patient can do, they can walk this far, it takes this much to help them out of bed, can't do stairs at all. Where can they go?" Modeling of such decision paths was envisioned to facilitate training and reduce possibilities of error. 
Lack ways to visualize progress of an individual over time or to match clinical and patient goals To the questions, 'How do you capture progress?' 'How do you identify what changes?' and 'How do you measure the importance of those changes?' there were a variety of responses suggesting that there is not a consistent and efficient way for the team to visualize progress. A nurse uses flow sheets that track multiple aspects in very fine detail for three shifts a day seven days a week. By comparing the records over the course of the patient's stay, she is able to 'see' change. One physiotherapist tried to address this by comparing the admission and discharge scores; however, this understanding of change is available only at the end of the patient's stay. Another physiotherapist elucidated the need for more efficient ways to understand change during the course of treatment and the implications in the discharge planning process by saying, "We used to check the rate of change through FIM. I've tried to look at how many FIM points changed per week. But the problem with that is that we would have to measure FIM every single week and it is too time consuming to add up the numbers, so it is done only at admission and discharge and [then] compared to see progress. Now we track individual components and $I$ keep them in my head: they started as assist of 2, FIM 1 and, where they are now... They need assist of 1 with FIM 3... I see that change but I don't add up the whole FIM and see how the numbers are changing."

She continued envisioning a practical way to track change, "I think that will be a good visual tool, if it was easy to use and to track, for a team to see at team rounds and take a look, ok .. How the patient is doing? Is there any plateau? Do we need to add something else? ... or to be able to say, Oh I didn't realize that patient has been stable or unchanging in two weeks." Furthermore, she explained that this tool could provide objective data that acknowledges the quality of rehabilitation to support strategic planning at the institutional level.

\subsubsection{Insights related to patient support}

Patients have memory issues so they require more coaching and reminding

A common topic in the discussion of issues with patients in this case scenario was the challenge of providing education and achieving compliance. Professionals explained that these types of issues often stem from the memory and retention difficulties that come with age, "Some people, 
it doesn't matter how many times you show them this exercise, they can't retain it to do it and they can't necessarily take the words and turn them into an exercise. Then those people you need to monitor them closely. We bring those people in, and it will be a one-on-one." Therefore, professionals expressed interest in forms for supporting patient education saying that this could help patients adhering to exercise routines and following safe sequences. Finding simple ways to remind patients was also desired; a physiotherapist explained that, "they are not allowed to cross their knees or their ankles often for a couple of months. That is very hard for a senior female because they do it all the time." P4. Nurses have to constantly remind patients of restrictions and precautions such as putting the brakes on the wheelchair before getting up, and grabbing the bar in a certain way.

\section{Difficult to monitor patient's participation and adherence to routines}

A common challenge faced by professionals is to detect issues that derive from patient lack of participation and miscalculations in the routine that affect the course of treatment. One occupational therapist, who also works at an outpatient rehab unit, explains that rehab primarily relies on what the patient does, but factors such as memory, motivation, and personality can greatly impact the rehab process. She explained that when patients are "dedicated, involved and very diligent at taking notes and keeping track of their progress, they offer a wealth of information" that is valuable for their decision making process. She also asserted that, unfortunately, these patients are rare. She envisions a tool to help monitor patient's physical routine, "It will be great to have them have a little diary I think so each exercise has a little picture and it has a calendar that says Monday, Tuesday, Wednesday, Thursday, Friday. Or it has the month and says: place a little square where it says 3 times ten, or I used 2 pound weights for this exercise. It is really good, it is really motivating actually for a patient to have that," She further explained that with a patient inclined to stop the routine due to sore muscles this might help in motivating them to keep exercising, "... then they will say you know, Tuesday I was really sore. I look back; what did you do with your exercises on Tuesday? Was it before your exercises or after? OK, let's look back... Oh look! You jumped up, another set of ten you are doing four times ten of this exercise and now you are sore in that same area as that muscle that you worked..." Another physiotherapist explained that having these data displayed in an easy-to-read format could also support communication with a patient when 
setting goals by showing, "This is where you started.. This is where you are at... This is what we think you are able to do safely... We think it will take this and this time before you can do xyz.."

Families need to be coached but limited time to do it

Most professionals see family day and family conferences as an important part of providing patient support by making caregivers aware of the patient's needs so that they can support the transition and continuation of care. However, due to time constraints, these activities are not carried out with every patient. "We used to do that with everyone, but with time constrains now, and larger case loads and a shorter length of stay we are not able to offer that as we used to".

This last section described the issues associated with patient education which suggest a need for tools to help clinicians in educating and coaching patients, maximizing their opportunity to practice by themselves and preparing them and their families for discharge. Table 6 summarizes the issues identified in section 4.3 which describe the opportunities to improve the processes mediated by artifacts.

4.3.1 Data management and information sharing

Large number and types of forms

Various inconsistent formats

Difficult of retrieving information

Learnability: complex scoring system

Limited to text, not flexible to sketch

No interdisciplinary data collection/access:

Non-interoperable data for decision support

Duplication of questions to the patient in assessment

4.3.2 Clinical decision support monitoring mobillty

Lack of tools to measure qualitative parameters

No data integration for a comprehensive big picture' of patient's status

No trend data to detect patterns of what is normal or normal variation in the rehabilitation process

4.3.3 Clinical deciston support: discharge planning

Absence of analysis tools for discharge planning

Lack of ways to visualize progress of an individual over time or to match clinical and patient goals

\subsubsection{Patient education}

Patients have memory issues so they require more coaching and reminding

Difficult to monitor patient's participation and adherence to routines

Families need to be coached but limited time to do it

Table 6. Summary of key findings in relation related to research question 3. 
This section presented the key findings that emerged associated with research question 3 . The underlying question during analysis looked for understanding how the current tools used by professionals support or, fail to support the clinicians' workflows. The findings revealed insights related to: data management and information sharing, decision support for mobility monitoring, decision support for discharge planning, and patient education. In turn, these insights helped understand the constraints under which clinical work is performed and define some of the professionals' needs and wishes that are relevant for design.

\subsection{Synthesis of findings: User Needs}

The following section provides a synthesis of the professionals' needs that emerged from the analysis of the three main research questions. All the resulting insights were grouped by affinity to reveal the most relevant needs as they relate to design. In turn, these were associated to the main shared activities identified in the process from admission to discharge: integrated assessments, mobility monitoring, discharge planning and patient and family preparation. Details are presented in Table 7 and the paragraphs that follow.

\begin{tabular}{ll} 
Needs in Interprofessional Care Practice & Bmergent Themes \\
\hline $\begin{array}{l}\text { Redundant and desynchronized data entry } \\
\text { Asynchronous data sharing and analysis } \\
\text { Usability issues with input devices that do not account for mobile and } \\
\text { sketching needs }\end{array}$ & $\begin{array}{l}\text { Integrated } \\
\text { assessment }\end{array}$ \\
$\begin{array}{l}\text { Difficult to capture subtle changes in mobility and function } \\
\text { No standard ways to assess monitor and visualize rate of change }\end{array}$ & $\begin{array}{l}\text { Mobllity } \\
\text { monttoring }\end{array}$ \\
$\begin{array}{l}\text { Complex process of evaluation of multidimensional factors to determine } \\
\text { discharge location } \\
\text { Limited tools to aid interdisciplinary goal setting and assess feasibility }\end{array}$ & $\begin{array}{l}\text { Discharge } \\
\text { planning }\end{array}$ \\
$\begin{array}{l}\text { Challenges to educate and coach patient and monitor participation } \\
\text { Need to instruct and involve family in the process }\end{array}$ & $\begin{array}{l}\text { Patient } \\
\text { preparation }\end{array}$ \\
$\begin{array}{l}\text { Constant display of updated patient's level of assistance } \\
\text { Coordinate interventions for continued care (for professional's agenda } \\
\text { and for patient's schedule) }\end{array}$ & $\begin{array}{l}\text { Communication \& } \\
\text { coordinatton }\end{array}$ \\
\hline
\end{tabular}

Table 7. List of needs identified and emergent themes. 
Integrated assessment: Need for integrated, flexible and easy-to-use recording instruments in assessment

Description: As shown in team workflow (refer back to figure 10), professionals in physiotherapy, occupational therapy and nursing collaborate extensively to conduct integrated assessments and treatment planning. These activities involved a great deal of data entry, analysis and sharing at both the disciplinary professional and interprofessional levels.

Tools: A close look at the tools used in the collaborative assessments demonstrated that very few recording instruments are well suited to meet the collective data entry and sharing needs. Each profession uses numerous outcome measures and standard tests such that data are recorded in varying formats, using inconsistent terms and scoring scales, as well as with a high level of redundancy. For the most part, professionals found current recording instruments rigid in that they did not allow observations to be recorded in sketch or graphical form. The thematic design of the FIM instrument, however, facilitated the capture of mobility performance as a whole, irrespective of the disciplinary inputs.

Mobility monitoring: Needs for tools to track, visualize and analyze patient mobility performance and rate of change

Description: It is critically important for diagnosis, treatment formulation and management of patient flow to monitor patient mobility and measure its rate of change to be able to care for post-operative hip surgery patients. Although all professions are concerned with mobility when treating post-hip surgery patients, monitoring mobility is always the core of the physiotherapists' work.

Tools: Three well-known simple-to-use scoring mechanisms, commonly used in the rehabilitation practice were used by physiotherapists for assessing aspects of transfers and ambulation: the BERG balance, the PFMP, and the Timed Up-and-Go (TUG). Of significant importance for design were the concerns expressed that these tools are mainly informed by observation, field tests and patient verbal reports and therefore are found to be limited in capturing subtle changes that are invisible to the naked eye. Physiotherapists and physicians consistently noted that these evaluative tools largely focus on capturing ability, (i.e., whether or 
not the individual is able to perform a given task) rather than capturing the quality of mobility (i.e., how well the patient performs such a task). For example, during a transfer from the bed to the wheelchair, the physiotherapists mentioned the need to closely capture detailed descriptions of hand positioning, symmetry of hip mobility and weight transfer. Similarly, more precise measures of weight-bearing status taken periodically were desired.

\section{Collaborattve discharge planning: Needs for shared care plans and evaluation of discharge} options

Description: Discharge planning is a collaborative task that starts at admission and iterates throughout the stay. It is a complex activity that involves everyone in the team and requires the careful tracking and constant evaluation of multidimensional factors to inform discharge decisions. Each professional contributes with reports on specific aspects (occupational therapy does home assessment, nursing does medication training, physiotherapy trains use of devices) which are discussed collectively and provide recommendations. The physician is ultimately the one who makes the decision. An essential component of discharge planning is goal setting with the patient (e.g., to be able to drive in two months) as it provides a measurable framework in which professionals can focus specific efforts and provides the team with a common purpose. Combining patient goals with their functional performance scores enables the discharge criteria established by general protocols to be tailored for each patient.

Tools: The weekly team rounds were instrumental in allowing the various professionals to comment on and contribute to collaborative care planning and delivery. Patient interviews conducted during assessments were a key instrument in goal setting allowing each professional to learn information about the patient such as lifestyle, environment to be discharged to, and resources available at discharge to customize the intervention. However, none of this information was recorded to enable later access and updating by other team members. For example, although all inquired about the patient's goals, and reported these to play a critical part in diagnosis, there was no common place to record them or easily retrieve them. This was mainly managed verbally. Furthermore, when asked to describe how they assess and keep track of all these variables used to decide on a discharge location, the professionals explained that they have developed a sort of 'logic' that everyone in the team knows well. Another critical tool 
for some professionals was a checklist form for keeping track of arrangements at discharge. However, there were conflicting responses about the consistent use of this form possibly because professionals trusted their experience to coordinate arrangements. This inconsistent use may have also been associated with the extensive number of forms used throughout the process. Discharge summaries for subsequent teams were provided at discharge, but these provided limited access to detailed assessment results or progress reports.

Patient and family discharge preparation: Needs for tools to support patient education and coaching

Description: The team-patient interaction is also one that design may have a great potential to support. While discharge is the end of the work process for the team, for the patient, this is only the beginning of a journey that often extends over several months before pre-operative mobility status is regained. The difficulties older adults experience in remembering safe sequences and practicing safe exercises on their own were a particular concern for several professionals. As one physiotherapist explained, "some people, it doesn't matter how many times you show them this exercise, they can't retain it to do it and they can't necessarily take the words and turn them into an exercise." To aid with this challenge, professionals would like to have more time to spend in educating and coaching patients. Currently, there are no occupational therapists or physiotherapists on weekends, so on those days the patient is not actively engaged in rehabilitation routines.

Tools: In describing strategies to prepare patients for discharge, professionals listed a 'weekend pass', which gave families and patients an opportunity to test the discharge plan, and address concerns before the official discharge. Some instructional illustrations made up part of this package. Family training in the form of a 'hands-on training day' was also offered to certain patients. Few artifacts that were analyzed supported patient preparation.

It is also worth noting that when describing assessments professionals often noted the need to be involved in a physical interaction with the patient whether by cueing with gestures or by assisting the patient during the transfer. Therefore, any means for data collection must consider these conditions as to enable and facilitate the data collection process without disrupting such 
interaction with the patient. Professionals would benefit from anything that will help them maximize their time with patients and increase opportunities to practice.

Communication and coordination: Needs for reliable communication about patient status and coordination of treatment and discharge

Description:Smooth workflow and collaboration relied on effective and efficient communication. Weekly formal meetings were instrumental in allowing the various members of the team to comment on, and contribute to, the planning and delivery of collaborative care.

Tools: A key communication tool among the professionals was the FIM scoring scale. With a score ranging from 1 to 7 , professionals were quickly able to convey the level of assistance required by a patient, which, in turn, reflected the stage in the rehabilitation process. Other communication was predominantly asynchronous and relied on a combination of the patient chart and a bedside bulletin board. The paper patient chart allows professionals to communicate and coordinate activities. However, as with any paper form, it poses limitations of accessibility and usability. For instance, it was difficult to access, to communicate with others about updates or to flag items for further discussion.

Bulletin boards were valuable for supporting inter-team as well as team-patient communication. These offered an effective way to communicate patient status at all times to all caregivers. The pictograms posted there by the physiotherapist were accompanied with handwritten notes about restrictions and recommendations. The bulletin board and the pictograms were found to be highly effective, providing quick reminders to the care team and, more importantly, conveying relevant data and risk factors to visiting family. In this way, these iconic symbols served as educational tools.

Coordination of activities was done mainly through two artifacts: office boards and the Interdisciplinary Integrated Plan of Care. The office board assisted in the coordination of activities at the intra-professional level. For example, during one of the interviews, it was observed that the two occupational therapists had posted a list of all their patients and their sessions, as well as the assigned rehabilitation assistants in the therapy rooms. Additionally, the Interdisciplinary Integrated Plan of Care was used at rounds to record the professionals' 
specific goals and to reflect the status and progress of the intervention. It then served two purposes: tracking progress by matching the reports of physical performance against the clinical goals and coordinating all professionals' activities.

In, sum the findings of the case study presented in this chapter revealed some of the professional needs of the four professionals collaborating in which design could prove beneficial. These are:

- need for integrated, convenient and easy to use recording instruments in assessment

- need for tools to track, visualize and analyze patient mobility performance and rate of change at individual and unit levels

- need for shared care plans and evaluation of discharge options

- need for tools to support patient education and coaching

- need for reliable \& continuous ways to communicate patient status and coordinate treatment and discharge

A discussion of the design opportunities resulting from the findings revealed in this chapter were reserved for the next chapter. 


\subsection{DISCUSSION}

This chapter intends to integrate the findings about the professionals' practice and needs with the findings from the literature. It is divided into seven sections. Section 5.1 presents a summary of main findings; 5.2, discusses insights revealed on interprofessional practices in geriatric rehabilitation; 5.3, details design insights and recommendations; 5.4, discusses the adequacy of the approach and the method; 5.5, provides insights for an approach to identifying opportunities in interprofessional care; 5.6, highlights the contributions of the research; and 5.7, provides some recommendations for future work.

\subsection{Summary of main findings}

This case study has revealed several important aspects of IPC practice in a short-term geriatric rehabilitation unit that are relevant for new product developers.

First, the findings identified the collective tasks and goals of four professions: medicine, nursing, physiotherapy and occupational therapy, which collaborate in the care process from admission to discharge of patients with hip-surgery. These findings were illustrated in a team workflow (Figure 10). The interview responses and archival research demonstrate a strong collaborative practice in which roles are highly interdependent and shared care plans are generated.

Second, an analysis was carried out to gain understanding of how current artifacts support practice. This revealed inconsistent and redundant instruments across the four professions that limit the ability to collaborate. For example, the existing means of managing patient information, most of which were designed for earlier models of care, remain predominantly paper-based, employ disparate recording instruments, and retain terminology and design native to each profession. This requires significant navigational overhead and lengthy documentation processes. It also involves considerable effort for professionals to be able to communicate and coordinate throughout the major shared activities. Thus, it results in a 
fragmented picture of patient status from which it is difficult to assess patient progress. In addition, and perhaps the most significant finding of this study, is the limited number of artifacts used collectively to support communication and coordination of activities. The FIM and a shared care plan were two important tools that facilitated collective process; however, the professionals reported several issues relating to design, usability and interoperability.

Third, the generation of the team workflow and the analysis of professionals' views uncovered some relevant needs of clinicians in particular areas across the continuum of care in the unit. A conceptual model was constructed to represent this continuum and the implications for design.

Figure 14 illustrates the continuum of care from admission to discharge of a patient with hip surgery. Four activities were identified requiring extensive team collaboration: integrated assessment, mobility monitoring, discharge-planning and patient preparation. These activities occur iteratively throughout the patient's stay.

In each of these activities, various levels of interaction among professionals were identified: intra-professional, inter-professional and patient-team. The various levels of interaction imply the existence of various information needs that must be addressed at individual and collective levels. For example, the monitoring of mobility is a particular domain of the physiotherapists and their assistants and, therefore, they will be concerned with detailed information about the patient's transfers and ambulation. At the same time, however, the nurse and the occupational therapist are also concerned with certain aspects of mobility, as they relate to the patient ability to perform daily tasks. The team-patient interaction was found relevant as well. In the particular case of patients with hip surgery, assessments are hands on, thus affecting the way professionals record data.

The core content of such collaboration is the information about patient functional performance, which is assessed and treated, in five major realms: mental, medical, physical, social and cognitive. The mental aspect is concerned overall with how a patient feels, acts, thinks and copes with the environment. The medical aspect looks at all health conditions of the patient that need to be managed including medication regimes. The physical aspect evaluates the physical ability to perform the daily tasks. The social aspect assesses the patient's ability to communicate and relate to others. Finally, the cognitive aspect relates, specifically, to the ability 
to concentrate and to retain and recall instructions. Data regarding these aspects are constantly collected and exchanged among professionals.

Smooth collaboration was found to rely on the quality of communication and coordination of all these iterative activities. Artifacts for information exchange are mediators of the multiple interactions across the activities and therefore may be enablers or inhibitors of communication and coordination.

In the conceptual model, the shaded area labeled communication and coordination is a particular concern for design. From this perspective, the four major shared activities can, therefore, been seen as areas for design opportunity. In general, the findings demonstrate a significant need for effective tools that support communication and coordination at the various levels of interaction. 


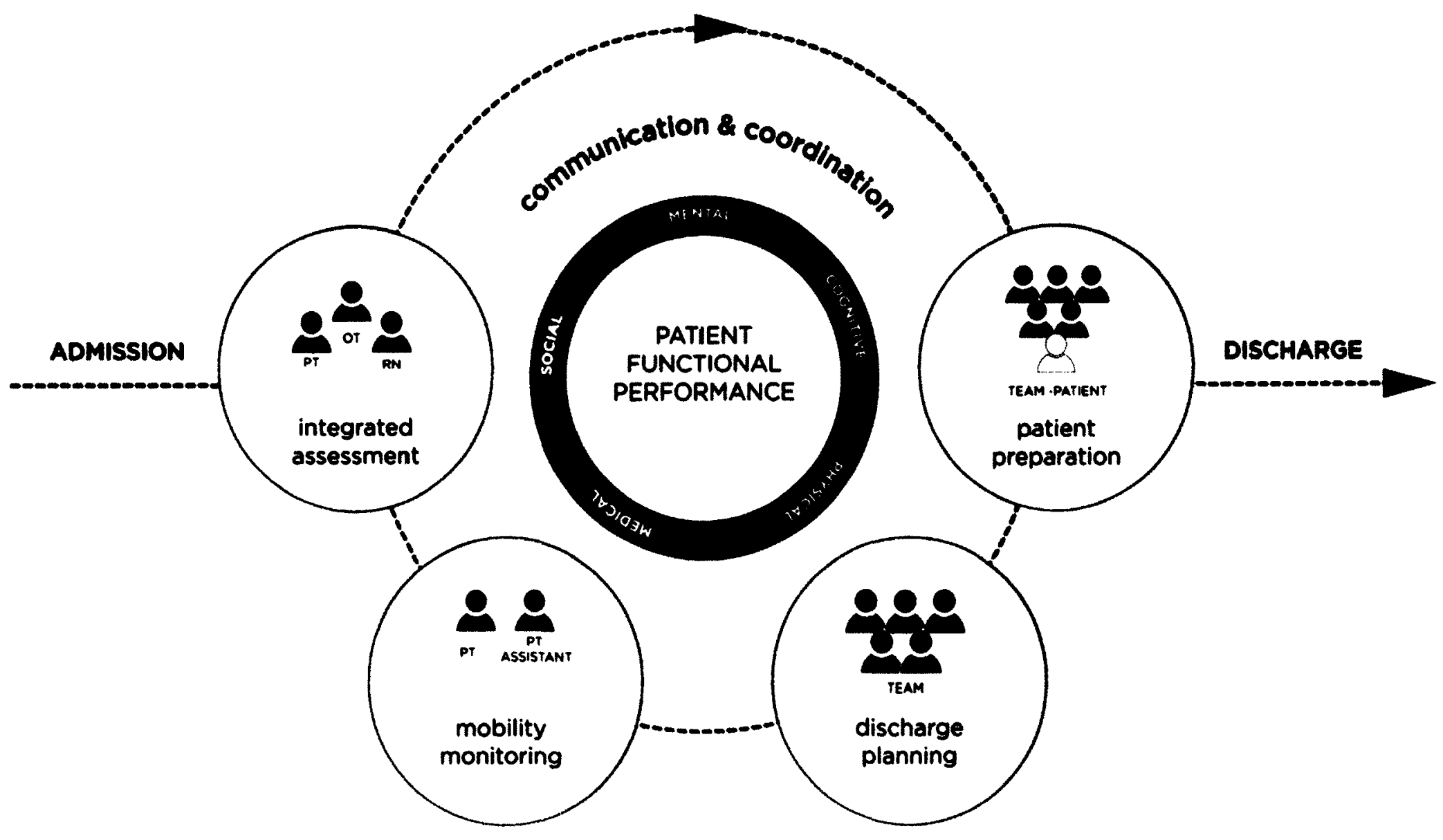

Figure 14. Conceptual model of relevant activities and interactions in the process from admission to discharge that pertain to design 


\subsection{Practices in IPC geriatric rehabilitation}

This section discusses insights revealed regarding interprofessional rehabilitation practice and the potential areas for improvement.

\subsubsection{Interprofessional rehabilitation practice}

The archival data from the institution and literature emphasizes the need for collaboration across professionals within and across clinical settings. The results of the present study showed that professionals do collaborate, and given common materials to document and exchange data do promote and facilitate the generation of a shared plan of care. However, the limited number of artifacts identified and the issues of usability, accessibility and interoperability reported may be limiting the team's ability to fully achieve such levels of collaboration.

The literature suggested that interprofessional care is achieved when professionals share decision making and goal-setting (HFO, 2007). This study contributes to the understanding of how this may actually be achieved. In this study professionals did set goals collectively, but they also did so individually. In fact, the shared goals resulted from a discussion and consideration of each professional's goals. Even though decisions were made collectively at rounds, interventions were still carried out independently by each profession. Therefore, it could be said that the new practice is a combination of multidisciplinary and interdisciplinary activities. Under the institutional guidelines for IPC implementation team members themselves re-design the care practice according to the characteristics of the unit. This might explain the combined strategy adopted by this team.

Different from prior studies, the results of this study contribute a workflow model of the interprofessional team's most relevant tasks and goals in the care process of geriatric patients with hip surgery in a short-term geriatric rehabilitation unit (refer back to figure 10). This model is unique. To the best of my knowledge, no evidence exists in the literature of such a type of representation of the four professional workflows in the rehabilitation practice. As such, it provides a basis for design researchers to understand the process, the actors and the interactions among them. In design research terms, this model provides a framework to identify potential user groups and their particular needs within the specific context of rehabilitation. This framework is a start in the understanding of the requirements emerging from the recently adopted collaborative practices. 


\subsubsection{Potential areas for improvement}

The in-depth analysis of the workflows yielded insights about the effectiveness of current tools to support the major activities and visions of how these can be improved. The four major tasks identified were common places at which the various clinicians' workflows intersect. Each of these tasks represents a critical point in which designers can concentrate to support the experience of the professionals and patients.

In all, these findings reflect a complex practice that involves a combination of strategies required to achieve shared decision making. For design, this complexity implies particular users and information needs that vary considerably according to the patient condition and the characteristics of the unit. This suggests that designers must understand the collective needs of a team. It also indicates that the unique needs of users including nurses, physicians, therapists and any specialty involved in geriatric care ought to be carefully considered. This is congruent with $\mathrm{HCl}$ theory which warns against designing products with the one-size-fits-all approach. The literature advises that understanding multiple clinicians' workflows and the intersections of those workflows is essential to the design of products that are usable and add value to the practice. As explained by Chapman (2013), the key is to design to workflows within context, people and processes, realizing that workflows do not happen in isolation and that professionals use a variety of tools to accomplish a task. Models and flowcharts help in understanding such complexity.

\subsection{Design insights and opportunities}

The results confirm the need for a better match between the clinician's workflow and the possibilities for technology. Therefore, the following passages are intended to detail design insights, highlight functional requirements for tools that may be developed and in some cases to offer concrete ideas of possible design solutions. Using the conceptual model as a framework Figure 14, the particular shared tasks of integrated assessment, mobility monitoring, discharge planning and patient preparation are seen as 'touchpoints' in which designing solutions based on design research insights may prove beneficial. These are essential for developing new products that support the collaborative practice of professionals involved in the rehabilitation care of hip surgery patients. 
Need for integrated, fiexible, consistent and easy-to-use recording instruments for integrated assessment

The interaction among occupational therapy, physiotherapy and nursing for integrated assessment is one that could be improved. The interdependency of these three roles demand comprehensive, consistent, and visual ways to record, analyze and share data in both integrated and in-depth professional assessments.

Design recommendation: A configurable EHR (Møller-Jensen, Pedersen and Simonsen, 2006) may reduce data redundancy and automate score conversion while presenting a more consistent and up-to-date picture of patient status as required by each professional. A system of this nature could meet the unique needs of each role as well as the collective needs of the various specialists, that is, it must use concise and unambiguous language, consistent terms and text formats. The thematic-based design of the FIM instrument could be used in tools to help all of the professionals involved to focus on overall aspects of the patient rather than on individual contributions. Data recording instruments must consider all other forms and means that professionals use, including observations and field tests, together with the sketch-like annotations of observations (where applicable). Furthermore, such tools should take into account the environment of use, which varies from bedside to gyms, therapy rooms and meeting rooms. Electronic group pages and work sheets (Vyt, 2008) presented on a portable device could enable data entry at the bedside, and allow for flagging items and virtual messaging among professionals.

\begin{tabular}{|ll|}
\hline Integrated assessment \\
\hline Roles: & $\begin{array}{l}\text { Occupational therapist, physiotherapist and nurse } \\
\text { Theeds: }\end{array}$ \\
& $\begin{array}{l}\text { There is data redundancy; a need to convert scores, and make data accessible to } \\
\text { for mobile environment and sketch-like annotations }\end{array}$ \\
Opportunity: & $\begin{array}{l}\text { Provide comprehensive, consistent, and visual ways to record, analyze and share } \\
\text { data during integrated assessment and treatment formulation } \\
\text { Integrated information management applications with thematic based-design that } \\
\text { use concise and unambiguous language, consistent terms and text formats, use of } \\
\text { standard abbreviations }\end{array}$ \\
\hline
\end{tabular}

Table 8. Design insights: integrated assessment 
Needs for tools to track, visualize and analyze patient mobility performance and rate of change

Physical therapy is assisted by a physiotherapist and various rehabilitation assistants who work hand-in hand with the patient. Their records of interventions are recorded collectively and are then shared with the team. The evaluative tools used in this case study were predominantly focused on assessing capacity; there was a clear absence of tools to measure performance. Parameters used by the physiotherapist in understanding the 'quality' of a patient rehabilitation, such as measures of weight-bearing status, posture and hand position during transfer and fatigue, were notably difficult to obtain. Finding ways to capture, visualize, and analyze this type of detailed information may help professionals understand the contributing factors to the success or lack of success in the rehabilitation process and better adapt the treatment plan to the unique needs of the patient.

The team also lacks mechanisms for measuring the rate of change of patient mobility. There were no systematic means to track specific parameters over time and visualize trends. This is essential for effective management of patient flow of the unit and for goal-setting with the patient. More objective measures for quantifying and visualizing progress at both the individual level and across the unit are desired. One could speculate that sensor technologies and data visualization techniques could be used here to enabling this type of monitoring. However, these technologies ought to work in conjunction with the current measures for evaluating mobility that professionals use and rely upon.

Design Recommendation As more advanced technologies for data integration and information visualization are developed, mechanisms for monitoring mobility should serve various purposes and user groups in this setting: a) to aid the physiotherapist in measuring parameters in greater detail including the quality of mobility in real time; b) to aid the team during rounds in quickly visualizing a patient's rate of change over a given period of time and to match performance with clinical goals; c) to aid the team in bed management and budgetary planning by visualizing trends and patterns within aggregate data of patient performance across the unit. 


\begin{tabular}{|ll|}
\hline Mobility performance monitoring \\
\hline Roles: & $\begin{array}{l}\text { Intra-professional (physiotherapist and PT assistants), inter-professional (full } \\
\text { team) } \\
\text { Needs: }\end{array}$ \\
$\begin{array}{l}\text { Limited mechanisms to measure aspects of performance of mobility; lack of } \\
\text { standard and easy to use ways to monitor rate of change; lack of mechanisms for } \\
\text { data visualization } \\
\text { Enabling the capturing, analyzing, visualizing and tracking changes of specific } \\
\text { parameters in patient mobility performance. } \\
\text { Mobility monitoring applications with imaging capabilities to capture data over } \\
\text { time }\end{array}$ \\
\hline
\end{tabular}

Table 9: Design insights: mobility performance monitoring

Needs for documenting shared plan of care and decision support in evaluation of discharge options

All four professional assessment results are considered for making discharge decisions. The current approach largely relies on experience and expertise. However, this approach presents a challenge as it may be seen as subjective, leaving room for medical error, and difficult for others to learn and apply.

Design recommendation Solutions for discharge care planning should support the iterative nature of such processes. Means to systematically record patient goals and assess discharge conditions, in a consistent format from the first day could personalize discharge criteria. In turn, this could be made available to all members of the team and be accessible for easy updating at team rounds. A tool could take the form of a decision tree and simply displaying the viability of discharging a patient to his/her home. These may inform decisions on an appropriate discharge location, and advise early planning of bed management when long-term care is required. Such a system can be used to generate a discharge checklist at the end of the hospital stay with minimal additional documentation required. 


\begin{tabular}{|ll|}
\hline Collaborattve discharge planning \\
\hline $\begin{array}{l}\text { Users: } \\
\text { Needs: }\end{array}$ & $\begin{array}{l}\text { Inter-professional (All team) } \\
\text { Complex evaluation of factors to determine safe discharge location and other } \\
\text { arrangements required; facilitate matching of clinical goals with patient } \\
\text { performance }\end{array}$ \\
Opportunities: & $\begin{array}{l}\text { Facilitate the evaluation of complex multidimensional data regarding a patient's } \\
\text { condition; to map and give advice on possible discharge location. Capture, analyze } \\
\text { and visualize changes in the patient's mobility performance } \\
\text { Recommendations: } \\
\text { Decision support systems to track multiple parameters consistently throughout } \\
\text { the stay, represent the possible paths, give recommendations on discharge } \\
\text { location and track the associated arrangements required. }\end{array}$ \\
\hline
\end{tabular}

Table 10. Design insights: Collaborative discharge planning

\section{Needs for tools to support patient education and coaching in preparation for discharge}

The patient-team interaction is another one that needs careful consideration. Mechanisms to remind patients of and guide them through exercise routines are desired to help maximize opportunities for the patient to regain mobility in the absence of personnel, as well as helping to increase compliance and participation.

Design recommendation One way of supporting patient education and coaching could be by means of visual illustrations and/or audio instructions that guide the patient step-by-step during exercise routines, and remind precautions for the patient to maintain safe practices. The physiotherapist could introduce the guide during one-on-one training sessions while in the unit showing the patient the exercises he or she is to do and the number of times to be completed between sessions. This would allow patients to become familiar with the exercise program and learn how to use the videos. Physiotherapists could slowly build a library of such videos and give them to patients both on weekends while in the rehabilitation unit, and also once they are at home. These coaching videos at home could be supplemented with the kind of diary that one of the respondents suggested, a calendar with a checklist of exercises to perform, which could be checked-off as the patient completes each routine. These records could then be made available to the professional to help understand progress, identify issues and further instruct the patient.

Expanding on this design idea, these patient instructional materials could be part of a patient toolkit, offering more information about the patient's condition, sharing ideas or testimonials on how others have managed their condition, providing a care plan with instructions and 
recommendations for caregivers, and a way to annotate concerns that may arise in the transition. Items in this toolkit could include:

- a medical summary of the patient's current status and detailed reports on progress and rate of change (which could be captured with the mechanisms previously described in this report), and goals to help subsequent caregivers in easily understanding the needs

- a checklist of discharge arrangements. This could be derived from the checklist discussed in previous sections

- a home care plan with a list of duties and tasks for family or caregivers

- a booklet with information about the patient's conditions, links to support both virtual and physical resources and communities.

- a questionnaire for caregivers to record issues and facilitate communication with outpatient rehabilitation professionals concerning patient progress and engagement in care.

\begin{tabular}{|c|c|}
\hline \multicolumn{2}{|c|}{ Patlent and familly discharge preparation } \\
\hline $\begin{array}{l}\text { Roles: } \\
\text { Needs: }\end{array}$ & $\begin{array}{l}\text { Intra-team (physiotherapist and PT assistants), inter-professional (full team) } \\
\text { Patient need to be reminder and coached ctosely. Limited opportunities to prepare } \\
\text { family for discharge. }\end{array}$ \\
\hline $\begin{array}{l}\text { Opportunities: } \\
\text { Recommendations: }\end{array}$ & $\begin{array}{l}\text { Support patient education instructing patients and caregivers prior to discharge to } \\
\text { A patient 'toolkit' with instructional videos, care plan for caregivers, informational } \\
\text { booklets, and feedback forms. }\end{array}$ \\
\hline
\end{tabular}

Table 11: Design insights: patient and family discharge preparation

\section{Needs for rellable communication about level of assistance for the patient and coordination of treatment}

One of the most significant findings of the study was that the great majority of artifacts used in the practice, were mainly used for information management and very few supported communication or coordination of shared responsibilities. For this reason this last point is represented in figure 14 with a larger gray circle that is interwoven with all the other four shared activities in the model.

All professionals have a high need for reliable and real-time ways to communicate among themselves. The existent forms of communication identified, despite limited, provided insights 
into effective ways to coordinate and communicate critical information. They suggest that more visual and automated communication and coordination tools could present real-time data and updates about patient status. It is possible to imagine that electronic and automated systems could facilitate the updating of information and the consistency of presentation, an issue discussed earlier in this section. Furthermore, the bedside is a strategic location for communication; both bulletin boards and TV screens have been used to convey information in that location.

Desion Recommendation Products could support more fluent collaboration among various health professions by means of interactive devices such as bedside terminals and wall displays. These would allow for teams and caregivers to readily access patient data enabling easy tracking of updates. Another function could be a bedside mechanism to coordinate scheduling and provide reminders of therapy sessions with the different professionals during the hospital stay.

Another communication tool that should be more often used is pictorial representations. The pictograms used were simple and were reported as highly effective. Given the effectiveness of these pictorial representations, the design of user interfaces and for products in this context could make use of them to capture, update and warn others of changes in the patient level of assistance.

Communication \& coordination

Roles: Inter-professional (All professionals in the team and assistants)

Needs: $\quad$ Communicate each patient's level of assistance to all caregivers at all times; communicate updates in real-time

Opportunity: $\quad$ Support inter-team communication and coordination of activities to provide continued care

Recommendations: Bedside and mobile mechanisms for constant display and easy update of each patient's status and risks factors; coordinate scheduling of interventions and other assignments

Table 12. Design insights: Communication and coordination

This section detailed the major design insights that resulted from the evaluation of all findings. Five types of needs were consolidated into design recommendations. 


\subsection{The adequacy of the approach and the method}

This study heeds the calls for systematically approaching the conceptualization stage of health technologies in NPD and involving the views of professionals in the process (refer to section 2.3). Taking a qualitative user research approach provided insights about the rehabilitation care practice and, more importantly, about the activities in the process that may be better supported by design. The researcher was able to maintain focus on understanding the problem by adhering to the systematic methods derived from $\mathrm{HCl}$.

The verification interviews were valuable for two reasons: they corrected misunderstandings in the interpretation of the team workflow and they helped to increase the rapport between researcher and professionals. Wilcox (2005) notes that this is an important aspect in conducting design research. In the first round of interviews of this study, healthcare professionals tended to describe the practice from an operational perspective (as described in protocols). The study, however, was intended to gain insight into the actual activities performed, and the professionals were hesitant to discuss issues or weaknesses in their practice. In the second set of interviews, professionals provided greater insight and description of their actual practice and revealed more information about breakdowns and 'pain points'. One may speculate that the difference was the result of building rapport with the researcher. It is possible that as the professionals gained an understanding of the intentions of a user design research study, they also gained such rapport. Therefore, they may have felt less vulnerable to being scrutinized. Being able to achieve such a level of conversation with professionals is essential for the design researcher as it is in these instances that gaps may be discovered and latent needs may be revealed.

Design research techniques used in this study shed light on possible ways for designers, design researchers, and developers to realize participation of clinicians in the development of health applications. Visual materials used in the verification interviews were critical for uncovering design insights and were essential in making the best of the time with professionals. The graphical representation of the team model was effective in clarifying misinterpretations. The video scenario depicting a fictitious character going through the journey was also valuable in discriminating between the main team goals and activities and the unique contributions of each professional. These two items combined served as catalysts for discussion, allowing the clinician to quickly relate to the scenario and focus on the tasks and goals. At the same time, this 
discussion provided an opportunity for the researcher to further probe into the 'pain points' of the process.

\subsection{An approach to design insight discovery in interprofessional care}

The findings from this thesis also revealed some important insights about the approach to user design research in interprofessional health care. These can be summarized into a set of design recommendations:

1. Scope the study to a particular shared work process: Care processes, particularly for chronic conditions, often involve a variety of care settings in which complex activities take place within and across the continuum of care. Choosing one setting and a team shared goal, e.g., the process from admission to discharge in short-term rehabilitation unit, facilitates the framing of design insights.

2. Scope the study to one health condition and a configuration of disciplines involved: The professional configuration of a team varies according to the patient condition and the complexity of the case. Focusing on a particular patient permits the researcher to define the boundaries of a process to be studied and to define the focus on particular user groups.

3. Educate clinicians on the purpose of design research: Clinicians are likely to be unfamiliar with design research and the intention behind the inquiry. Talking about it and using visual design tools helps build rapport.

4. Map the process to represent their work and verify with professionals: Map the major tasks and goals of the roles in the process. Verifying the interpretation of the model with professionals is useful in two ways: it helps clarify misunderstandings and provides an opportunity to probe deeper into identified gaps or complexities.

5. Analyze the artifacts used: Understand the current ways of performing a task and identify the current technologies that support each of these tasks.

6. Get their views about the artifacts: Once presented with a model of the major tasks, professionals can more easily reflect on how well the artifacts support their goals at both the individual and collective level. 
7. Understand the context and organizational factors: Professionals perceptions and descriptions are influenced by the various environmental factors surrounding their practice. Do archival research to understand other forces that may explain or influence the way they practice.

These first five sections in the discussion chapter have summarized the findings of the study and discussed their significance to the body of literature reviewed. Design insights were also discuss in detailed for each of the areas in which design could prove beneficial. The following paragraphs make the contributions of this investigation explicit and provide recommendations for future work.

\subsection{Contributions}

This research provides three main contributions to the field of design for healthcare. First, it provides a detailed model of the interprofessional workflow of the relevant tasks and goals throughout the integrated care process in a specific healthcare situation. This workflow model adds to the practice of collaborative decision making in this rehabilitation process case. It represents a process that has been recently adopted and, therefore, is not easily described to new professionals who may join the team.

Second, it provides a conceptual model that serves as a framework for understanding the relations among collective tasks and the various professional interactions across the continuum of care, as well as, the most relevant data used in the process.

Third, it yields design recommendations for the specific activities in the process that offer practical knowledge for anyone involved in the development of new applications. Many design insights emerged offering exciting opportunities for information and communication technologists and biomedical engineers. Software developers can use the recommendations as a guide to determine product functions and create scenarios of possible workflows. 


\subsection{Future work}

There are several ways in which the research conducted for this thesis could be expanded.

While conducting this user design research some concrete ideas of possible concept solutions emerged. These design ideas could take the form of future design projects to develop custom applications that support the shared processes for this group of professionals in rehabilitation care, for example:

- An electronic shared care plan to integrate data among occupational therapist, physiotherapist and nurse for interprofessional assessment, goal setting and treatment formulation.

- A bedside wall display to facilitate a) inter-team communication and coordination of activities to provide continued care; b) support patient education and coaching.

- A clinical decision support system to facilitate the evaluation of complex multidimensional data regarding patient's condition and suggest on possible discharge locations and associated risks.

- A system that enables capturing, analyzing and visualizing the rate of change in patient's mobility performance over a given period of time.

- A type of patient 'passport', that is, a discharge package to inform and instruct patients and caregivers

An application for supporting integrated decision making in the particular case of a post-hip surgery patient, could present the physiotherapists with detailed mobility parameters. This would enable continuous and easy tracking and comparison. This information would be available to the occupational therapist and the nurse, as required. The occupational therapist would have a summary of relevant mobility parameters associated with the Activities of Daily Living assessment, and the nurse would have an easy way to consolidate the multiple assessment records for three daily shifts reporting on cognition, transfer and mobility, toileting self-care, continence and pain. Such application would make easy the translation of such individual units into a comprehensive mobility score. It will also present information that they all share including patient's goals, clinical goals, discharge environment and circumstances. 
Another study could investigate the patient journey from the patients' and caregivers' perspectives. This study showed that the patient-team interaction is highly relevant as patient participation increases in the decision-making process of care. Specifically, studies could observe training sessions with the patient in order to understand the steps followed by the physiotherapist, rehabilitation assistant and the patient, the types of instructions given and the nature of artifacts used for guiding the patient. Design efforts should take their views into account as they ultimately are who will benefit from efficient workflows in the provision of care.

Lastly, a study could assess other teams with similar characteristics to determine the applicability of the conceptual model that emerged from this study. 


\section{CONCLUSION}

This user design research has demonstrated that combining the skill set of two user-driven design disciplines, Human Computer Interaction and Industrial Design, deepens the ability to uncover design insights that are essential in the conceptualization of new products.

The qualitative set of methods used for this user design investigation turned out to be useful in identifying the needs of the different professionals who collaborate in this healthcare setting. Talking to clinicians and modeling the work practice provided the rich details necessary to build the series of models that represent the professional workflows and the points of intersection among them. These points of intersection are critical for product designers as they frame the potential areas in which design intervention could prove beneficial. The findings revealed 'pain points' and design shortcomings of the current tools, as well as insights on the way professionals deal with them in this particular setting. Many of the artifacts used, which were designed for prior models of care, need to be redesigned to facilitate new documentation and communication processes.

The results of this user design research come at a time of change for healthcare professionals. As the healthcare system finds its way into a new structure, professionals are learning to work in a more collaborative way to make shared decisions. This rapid changing space offers exciting opportunities for design research to help conceptualize products that, innovatively and sensibly, meet the needs of those devoting their lives to the provision of quality care. 


\section{REFERENCES}

Alberta Health Services (n.d). Improving the Home Discharge Process from Acute Care Neuroscience Units.

American Academy of Family Physicians (AAFP) "Patient-Centered Medical Home" May 2008 [http://www.aafp.org/online/en/home/policy/policies/p/patientcenteredmedhome.htm] Last accessed 20 December 2012.

Australia Government. New South Wales Health. NSW. Rehabilitation Model of Care. December 2010

[http://www.archinetau/documents/resources/models/rehab_redesign/rehabilitationmoc.pdf] Last accessed 1 April 2013.

Bates, D.W.: Using information technology to reduce rates of medication errors in hospitals. BMJ 320, 788-791 (2000)

Beyer, Hugh, and Karen Holtzblatt. 1998. Contextual Design: Defining customer-centered systems. San Francisco, California: Morgan Kaufmann.

Bijker, Wiebe E., Thomas Parke Hughes, and T. J. Pinch. The Social Constructions of Technological Systems: New Directions in the Sociology and History of Technology. MIT Press, 1989.

Bruyère Continuing Care, (n.d.) "Rehabilitation Care, Bruyère is there." Brochure.

Bruyère Continuing Care. "Transitioning Clinical Teams to an Interprofessional Model of Care (IPC). A 'How To Manual'". February 2010

Bødker, Keld, Finn Kensing, and Jesper Simonsen. 2004. Participatory IT design : Designing for business and workplace realities. Cambridge, Mass: MIT Press.

Burk, 2012. "Smarter healthcare in Canada: Redefining Values and Success" July 2012. Healthcare Industry. Last accessed on March 20, 2013. IBM Corporation [http://www.ibm.com/smarterplanet/global/files/ca_en_us_healthcare_ca_brochure.pd f]

Campbell, E. M, D. F Sittig J. S Ash, K. P Guappone, and R. H Dykstra. "Types of Unintended Consequences Related to Computerized Provider Order Entry." Journal of the American Medical Informatics Association 13, no. 5 (September 1, 2006): 547-556. doi:10.1197/jamia.M2042.

Canadian Institute for Health Information (CIHI). "Clients Transitioning From Inpatient Rehabilitation to Complex Continuing Care or Home." Series NRS Analyses in Brief. 26 April 2007. 
Castillo, Helen M., and David C. Hall. "Discharge Planning Needs for Hip Fractures: A Descriptive Study." Journal of Applied Gerontology 6, no. 3 (September 1, 1987): 301-312. doi:10.1177/073346488700600305.

Chan, Marie, Eric Campo, Daniel Estève, and Jean-Yves Fourniols. "Smart Homes - Current Features and Future Perspectives." Maturitas 64, no. 2 (October 20, 2009): 90-97. doi:10.1016/j.maturitas.2009.07.014.

Chapman, Lorraine. "The Gist of NIST". CapCHI, presentation. January 2013

Cooper, Alan, Robert Reimann, and David Cronin. About Face 3: The Essentials of Interaction Design. 1st ed. Wiley, 2007.

Cooper, Rory A., Brad E. Dicianno, Bambi Brewer, Edmund LoPresti, Dan Ding, Richard Simpson, Garrett Grindle, and Hongwu Wang. "A Perspective on Intelligent Devices and Environments in Medical Rehabilitation." Medical Engineering \& Physics 30, no. 10 (December 2008): 1387-1398. doi:10.1016/j.medengphy.2008.09.003.

Crabtree, Andy, Terry Hemmings, Tom Rodden, Keith Cheverst, Karen Clarke, Guy Dewsbury, John Hughes, and Mark Rouncefield. "Designing with Care: Adapting Cultural Probes to Inform Design in Sensitive Settings." In Proceedings of the 2004 Australasian Conference on Computer-Human Interaction (OZCHI2004), 4-13, 2003. http://www.mrl.nott.ac.uk/ axc/documents/papers/OzCHI03.pdf.

Creswell, John. Qualitative Inquiry and Research Design : Choosing Among Five Traditions. 2nd ed. Thousand Oaks: Sage Publications, 2007.

Crispim-Junior, C.F., V. Joumier, Y-L. Hsu, M-C. Pai, P-C. Chung, A. Dechamps, P. Robert, and F. Bremond. "Alzheimer's Patient Activity Assessment Using Different Sensors." Gerontechnology 11, no. 2 (June 14, 2012). doi:10.4017/gt.2012.11.02.597.678.

Cross, Nigel. Designerly Ways of Knowing. 1st Edition. Springer, 2007.

D'Amour, Danielle., Marcela Ferrada-Videla., Leticia San Martín-Rodriguez, and MarieDominque Beaulieu (2005). The conceptual basis for interprofessional collaboration: Core concepts and theoretical frameworks. Journal of Interprofessional Care, (May)Supplement 1,116-131.

Dishman, E. "Inventing Wellness Systems for Aging in Place." Computer 37, no. 5 (2004): 34-41. doi:10.1109/MC.2004.1297237.

Hall, Pippa, 2005. Interprofessional teamwork: Professional cultures as barriers. Journal of Interprofessional Care, 19, no. S1: 188-196.

Harnett, Brett, "Patient Centered Medicine and Technology Adaptation." In E-Health, Assistive Technologies and Applications for Assisted Living: Challenges and Solutions, ed. Carsten Rocker and Martina Ziefle, 1-22. New York: Medical Information Science Reference, 2011. 
Harrison, Anne L., and Lynn English. "Interdisciplinary Health Assessment of the Older Individual: A Conceptual Framework for Curricular Integration." Journal of Physical Therapy Education 15, no. 2 (July 1, 2001): 18.

Harrison, M.I., Koppel, R., Bar-Lev, S.: Unintended Consequences of Information Technologies in Health Care-An Interactive Sociotechnical Analysis. Journal of the American Medical Informatics Association 14(5), 542-549 (2007)

Hayrinen, K. "Definition, Structure, Content, Use and Impacts of Electronic Health Records: A Review of the Research Literature." International Journal of Medical Informatics 77, no. 5 (2008): 291-304.

HealthQualityOntario (HQ0). Quality Improvement Guide. [http://www.hqontario.ca/portals/0/Documents/qi/qi-quality-improve-guide-2012en.pdf] Last accessed April 15, 2013

Hermens, Hermie J, and Miriam M R Vollenbroek-Hutten. "Towards Remote Monitoring and Remotely Supervised Training." Journal of Electromyography and Kinesiology: Official Journal of the International Society of Electrophysiological Kinesiology 18, no. 6 (December 2008): 908-919. doi:10.1016/j.jelekin.2008.10.004.

Horsky, Jan, Gordon D. Schiff, Douglas Johnston, Lauren Mercincavage, Douglas Bell, and Blackford Middleton. "Interface Design Principles for Usable Decision Support: A Targeted Review of Best Practices for Clinical Prescribing Interventions." Journal of Biomedical Informatics 45, no. 6 (December 2012): 1202-1216. doi:10.1016/j.jbi.2012.09.002.

Howard Alex. "A marriage of data and caregivers gives Dr. Atul Gawande hope for health care" O'Reilly Radar August 31, 2012 [http://radar.oreilly.com/2012/08/a-marriage-of-dataand-caregivers-gives-dr-atul-gawande-hope-for-health-care-html]. Last accessed 3 April 2013.

International Business Machines (IBM) Corporation. "IBM Watson" CT004, April 11, 2012. http://www-03.ibm.com/innovation/us/watson/watson_in_healthcare.shtml.

International Classification of Functioning. Disability and Health (ICF) n.d World Health Organization.Geneva. [Retrieved from www.who.int/classification/icf.] Accessed Feb 2011.

Irwin, J Y, M H Torres-Urquidy, T Schleyer, and V Monaco. "A Preliminary Model of Work During Initial Examination and Treatment Planning Appointments." British Dental Journal 206, no. 1 (January 10, 2009): E1; discussion 24-25. doi:10.1038/sj.bdj.2008.1151.

Jones, John Chris. Design Methods. John Wiley \& Sons, 1992.

Jones, Linda., Daniel Way, and Neill B. Baskerville 2001. Improving the effectiveness of primary health care through nurse practitioner/family physician structured collaborative practice. Project Number NA342 March 31, 2001 Final Report to the Health Transitions Fund, Ottawa, Ontario. University of Ottawa: 1-57. 
[http://tools.hhrrhs.ca/index.php?option=com_mtree\&task=att_download\&link_id=4894\& cf_id=68\&lang=en] Accessed 21 December 2012.

Keene, G S, M J Parker, and G A Pryor. 1993. "Mortality and Morbidity After Hip Fractures." BMJ Clinical Research Ed. 307, no. 6914 : 1248-1250.

Kim, Jongbae, and David Wilemon. "Focusing the Fuzzy Front-end in New Product Development." R\&D Management 32, no. 4 (2002): 269-279. doi:10.1111/14679310.00259.

King, Rachael. "One Stanford doctor wants to focus on real patients, not iPatients" The Wall Street Journal. US. Edition. 26 October 2012.

[http://blogs.ws].com/cio/2012/10/26/one-stanford-doctor-wants-to-focus-on-realpatients-not-ipatients/?KEYWORDS=medical+records] Accessed 26 December 2012.

Koen et al. (2001), Providing clarity and a common language to the 'fuzzy front end'. Research Technology Management, 44 (2), p.46-55

Kolko, Jon. Exposing the Magic of Design: A Practitioner's Guide to the Methods and Theory of Synthesis. USA: 1st ed. Oxford University Press2011.

Lehoux, Pascale. The Problem of Health Technology. Great Britain: 1st ed. Routledge, 2006.

Leonard, Kevin. "Critical Success Factors Relating to Healthcare's Adoption of New Technology: A Guide to Increasing the Likelihood of Successful Implementation." 2 (4) 2004:72-81 Longwoods Publication. Accessed April 27, 2013. http://www.longwoods.com/content/16194.

Löwgren, Jonas, and Erik Stolterman. Thoughtful Interaction Design: A Design Perspective on Information Technology. Cambridge, Massachusetts The MIT Press, 2004.

Lucas, H.C.: Why Information systems fail. Columbia University Press, New York (1975)

Mickan, Sharon M., Sylvia A. Rodger. 2005. Effective Health Care Teams: A model of six characteristics developed from shared perceptions. Journal of Interprofessional Care 19, no. 4: 358-370.

Ministry of Health and Long-Term Care, Canada. HealthForceOntario. "Implementing Interprofessional Care in Ontario," May 2010. IPC Strategic Implementation Committee.

Ministry of Health and Long-Term Care, Canada. HealthForceOntario. "Interprofessional Care: A Blueprint For Action" July 2007. IPC Strategic Implementation Committee. [http://wwwhealthforceontario.ca/UserFiles/file/PolicymakersResearchers/jpcblueprint-july-2007-en.pdf] Last accessed 15 December 2012.

Minister of Public Works and Government Services Canada, Public Health Agency of Canada. Report on Seniors' Falls in Canada Cat. No. HP25-1/20005E (2005). 
Møller-Jensen, John, Ivan Lund Pedersen, and Jesper Simonsen. "Measurement of the Clinical Usability of a Configurable EHR." Studies in Health Technology and Informatics 124 (2006): 356-361.

Naglie, Gary, Catherine Tansey, James L. Kirkland, Darryl J. Ogilvie-Harris, Allan S. Detsky, Edward Etchells, George Tomlinson, Keith O'Rourke, and Barry Goldlist."Interdisciplinary inpatient care for elderly people with hip fracture: A randomized controlled trial." Canadian Medical Association Journal (CMA/) no.167(1) Uuly 2002): 25-32.

Norman, Donald A. The Psychology Of Everyday Things. Basic Books, 1988.

Olupeliyawa, A. Chris Hughes and Chinthaka Balasooriya. 2009. A review of the literature on teamwork competencies in healthcare practice and training: Implications for undergraduate medical education. South East Asian Journal of Medical Education Vol. 3, no2 : 61-78.

Papadimitropoulos Emmanuel, Peter Coyte, Robert Josse, Carol Greenwood. Current and projected rates of hip fracture in Canada. Canadian Medical Association Journal. 1997; 157:1357-1363.

Pennsylvania Patient Safety Authority. The Role of the Electronic Health Record in Patient Safety Events. Pennsylvania Patient Safety Advisory 9, no. 4 (December 2012):113-121 [http://patientsafetyauthority.org/ADVISORIES/AdvisoryLibrary/2012/Dec;9\%284\%29/ Pages/113.aspx]

Pew, Richard W., and Susan B. Van Hemel, eds. Technology for Adaptive Aging. National Academies Press, 2004.

Privitera, Mary, Todd Abruzzo, and Andrew Ringer. "Visual Mapping of Clinical Procedures Using Ethnographic Techniques in Medical Device Design." In An Ethnography of Global Landscapes and Corridors, edited by Loshini Naidoo. InTech, 2012. [http://www.intechopen.com/books/howtoreference/an-ethnography-of-globallandscapes-and-corridors/visual-mapping-of-clinical-procedures-using-ethnographictechniques-in-medical-device-design-.]

Public Health Agency of Canada. "An environmental scan of data sources for seniors falls in Canada" April 2007. Prepared by Alberta Centre for Injury Control \& Research (ACRICR). School of Public Health University of Alberta.

Reeves, Scott,. Merrick Zwarenstein, Joanne Goldman, Hugh Barr, Della Freeth, Marilyn Hammick, Ivan Koppel 2001. Interprofessional education: effects on professional practice and health care outcomes [review]. Cochrane Database of Systematic Reviews 2008, Issue 1. Art. No.: CD002213.

Robeznieks, Andis. "In No Big Hurry. Physicians Still Slow to Adopt EMR Systems: Survey." Modern Healthcare 35, no. 38 (2005): 17. 
Rogers, Yvonne, Helen Sharp, and Jenny Preece. Interaction Design: Beyond Human - Computer Interaction. 3rd ed. Wiley, 2011.

Saffer, Dan. Designing for Interaction: Creating Innovative Applications and Devices (2nd Edition). 2nd ed. New Riders, 2010.

Sainfort, Francois. Julie A Jacko, Paula J. Edwards, Bridget C. Booske. Human-Computer interaction in health care. In The Human Computer Interaction Handbook (Ed.) by Andrew Sears and Julie Jacko, 2008. no. 33: 661-676

Sanders, Elizabeth B.N. and Peter Jan Stappers, "Co-creation and the New Landscapes of Design" 2008. [http://www.maketools.com/articlespapers/CoCreation_Sanders_Stappers_08_preprint.pdf]

Sanders, Elizabeth B.N. (2006) Design Research in 2006. Design Research Quarterly, V:1:1, Design Research Society, September 2006.

Schön, Donald A. The Reflective Practitioner: How Professionals Think In Action. 1st ed. Basic Books, 1984.

Schuler, Douglas, and Aki Namioka. Participatory design: Principles and practices. Hillsdale, N.J.: L. Erlbaum Associates, 1993.

Sinclair, Lynne B, Lorelei A Lingard, and Ravindra N Mohabeer. "What's so Great About Rehabilitation Teams? An Ethnographic Study of Interprofessional Collaboration in a Rehabilitation Unit." Archives of Physical Medicine and Rehabilitation 90, no. 7 (July 2009): 1196-1201. doi:10.1016/j.apmr.2009.01.021.

Strasser, Dale C, Judith A Falconer, Alan B Stevens, Jay M Uomoto, Jeph Herrin, Susan E Bowen, and Andrea B Burridge. "Team Training and Stroke Rehabilitation Outcomes: a Cluster Randomized Trial." Archives of Physical Medicine and Rehabilitation 89, no. 1 Uanuary 2008): 10-15. doi:10.1016/j.apmr.2007.08.127.

Suri, J. Fulton. "Informing our intuition: Design research for radical innovation." Rotman Magazine, March 2008.

Tang, Charlotte, and Sheelagh Carpendale. "Supporting Nurses' Information Flow by Integrating Paper and Digital Charting." In ECSCW 2009, edited by Ina Wagner, Hilda Tellioğlu, Ellen Balka, Carla Simone, and Luigina Ciolf, 43-62. Springer London, 2009. http://link.springer.com/chapter/10.1007/978-1-84882-854-4_3.

Tang, Charlotte, and Sheelagh Carpendale, (2010) Human-Centered Design of E-Health Technologies. IGI Global, 2010. Ziefle, Martina, and Carsten Röcker, eds. http://www.igiglobal.com/chapter/human-centered-design-health-information/50790.

Tang, P C, M A Jaworski, C A Fellencer, M P LaRosa, J M Lassa, P Lipsey, and W C Marquardt. "Methods for Assessing Information Needs of Clinicians in Ambulatory Care." Proceedings / 
the ... Annual Symposium on Computer Application [sic] in Medical Care. Symposium on Computer Applications in Medical Care (1995): 630-634.

Terry, Amanda L., Judith Belle Brown, Louisa Bestard Denomme, Amardeep Thind, and Moira Stewart "Perspectives on Electronic Medical Record Implementation After Two Years of Use in Primary Health Care Practice." The Journal of the American Board of Family Medicine 25, no. 4 (July 1, 2012): 522-527. doi:10.3122/jabfm.2012.04.110089.

Vyt, Andre. "Interprofessional and Transdisciplinary Teamwork in Health Care" Diabetes/Metabolism Research and Reviews 24, no. S1 (2008): S106-S109. doi:10.1002/dmrr.835.

Wilcox, Stephen. Ethnographic Methods for New Product Development In Designing Usability into Medical Products edited by Michael E. Wiklund and Stephen B. Wilcox. CRC Press, 2005.

Winters, Jack M. 2002. Telerehabilitation Research: Emerging Opportunities. Annual Review of Biomedical Engineering 4, no. 1 (August 2002) : 287-320.

Wu, Jen-Her, Wen-Shen Shen, Li-Min Lin, Robert A. Greenes, and David W. Bates. "Testing the Technology Acceptance Model for Evaluating Healthcare Professionals' Intention to Use an Adverse Event Reporting System." International Journal for Quality in Health Care 20, no. 2 (April 1, 2008): 123-129. doi:10.1093/intqhc/mzm074.

Yaffe, Mark, Iryna Dulka and Jordan Kosberg, 2001. Interdisciplinary Health-care Teams: What Should Doctors Be Aware Of? The Canadian Journal of CME. 13(5):153-160.

Zijlstra,Wiebren., Clemens Becker., Klaus Pfeiffer. "Wearable Systems for Monitoring Mobility Related Activities: From technology to Application for Healthcare Services" In E-Health, Assistive Technologies and Applications for Assisted Living: Challenges and Solutions, ed. Carsten Rocker and Martina Ziefle, 1-22. New York: Medical Information Science Reference, 2011. 


\section{APPENDIX A}

\section{Recruitment Emails Inquiry Interviews}




\section{Health care profesetonals already known to the reseancher \\ Email Subject: Soliciting Your Participation for Study - Hip Replacement Rehab}

Dear <insert name>

As you may know, I am currently working on my master's thesis at Carleton University in the School of Industrial design.

As part of my thesis, I am doing a study seeking to identify the needs of health care team members and other caregivers of post-operative hip-replacement patients in order eventually to provide a useful and usable decision support tool for crucial care-related decisions, for example, concerning when to discharge a patient.

For the study, I need to interview experts with experlence in geriatric rehabilitation and/or hip replacement rehabilitation.

I would like to invite you to participate. Please send me an email or call me ?' willing to take part in the study.

If this is not feasible, then perhaps you know of someone who might be interested. If so, please let me know.

l've appended the notice for the study at the end of this email with some of the details for the study participation.

Thanks in advance,

Diana Isaza Shelton

dibarran@connect.carleton.ca 


\section{Health cure experts recommended by other contacts}

Emall Subject: Looking for experts in gerlatric rehabilitation.

Good morning/afternoon <insert name>,

My name is Diana lsaza Shelton. I am currently working on my master's thesis at Carleton University in the School of Industrial design.

As part of my thesis, I am doing a study looking at decision-making in post-operative care of hip replacement patients.

<insert name of person who suggested contact suggested that you might be interested in being involved with my research project.

For the study, I need to interview health care experts. 1 am looking for practitioners in OT or physiotherapy with experience in geriatric rehabilitation who would be willing to participate in the study.

I would like to invite you to participate, or if you could suggest someone who might be willing to participate please send me an email or call me I ).

Thank you very much in advance for your help.

\section{Kind regards}

Diana Isaza Shelton

dibarran@connect.carleton.ca 


\section{APPENDIX B}

\section{Recruitment Emails Verification Interviews}


Health care professionals who had participated in inquiry interviews

Emall Subject: Decision Making in Geri-rehab - Carleton Grad study

Phone/Email

Good afternoon [practitioner's name],

I'm Diana, the Master of Design student at Carleton who interviewed you last October about current practices and decision-making in geri-rehab. I appreciate the time you took to participate in my study. Your answers were very valuable.

Now that I've gained some understanding of the process, I am hoping I can review it with you. I've created a diagram that reflects the main steps and the information used in each step of the process and now l'd like to ask you some questions to verify if my understanding reflects the process correctly.

This will take 30 minutes. I will bring some print outs and I'll ask you some questions based on them.

If you can assist me with this, l'd like to arrange some time this or next week to meet. Please let me know your availability. I am fairly flexible.

Many thanks in advance!

Diana Isaza Shelton 
APPENDIX C

Additional questions 
Additional questions to health care personnel with knowledge in both the assistive technologies and geriatric care:

1. What are the main challenges for the team supporting hip replacement rehabilitation in elderly patients?

2. What are the major pain points of assessing when a patient with hip replacement is ready for discharge?

3. Who is generally involved in the decision of discharging a patient from hospital after surgery? What is each expert's role?

4. What technologies do you use or know of that support the rehabilitation care delivery for hip $R$ patients?

5. What do you think the smart mat is capable of telling with regard to discharging a patient from hospital?

6. Have you thought about other data that might be valuable to support the team decision-making process? 
APPENDIX D

Debriefing Script 


\section{Dehriefing}

Thank you very much for participating in this study. The information you have provided will be pooled with similar information obtained from other participants. All the data will be analyzed together and used to further our understanding of the assessment, treatment, and post-operative care of elderly hip replacement patients. Your anonymity is assured; no individual will be recognizable in the aggregated data. The coded raw data will only be available to the researchers involved in this study.

Thank you again very much for your time.

The following personnel are involved in this research project and may be contacted at any time: Diana Isaza Shelton (principal researcher) dibarran@connect.carleton.ca , Dr Gitte Lindgaard (Psychology Faculty Advisor) gitte_lindgaard@carleton.ca 613-520-2600 ext. 2255, Professor Lois Frankel (Industrial Design Faculty Advisor) Lois_Frankel@carleton.ca 613-520-5675. If you have any ethical concerns about how this study was conducted, please contact Dr. Monique Sénéchal (Chair of the Carleton University Ethics Committee for Psychological Research) monique_senechal@carleton.ca 613-520-2600, ext. 1155, If you have any other concerns about this study, please contact Dr. Thomas Garvey (Director of the School of Industrial Design), thomas_garvey@carleton.ca 613-520-5674

This study has received clearance by the Carleton University Psychology Research Ethics Board (11-xxx). Please use this number if you need to contact the Chair of the Department or Chair of Ethics Committee concerning this study. Thank you. 


\section{APPENDIX E \\ Informed consent form Inquiry Interviews}




\section{Informed Consent Form}

The purpose of an informed consent is to ensure that you understand the purpose and your involvement in the study. After reading it, you should be able to determine whether or not you wish to participate in this study.

Study Purpose: The purpose of this study is to understand best practices and identify currently available decision-support materials for health care teams and other caregivers of post-operative hip-replacement patients in order to understand how the process underlying the decision to discharge such a patient might be improved.

Research Personnel: The following personnel are involved in this research project and mav be contacted at any time: Diana Isaza Shelton (principal researcher) dibarran@connect.carleton.ca

Gitte Lindgaard (Psychology Faculty Advisor) gitte_lindgaard@carleton.ca 613-520-2600 ext. 2255, Professor Lois Frankel (Industrial Design Faculty Advisor) Lois_Frankel@carleton.ca 613-520-5675.

Tasks and Duration: You are asked to take part in an interview to help us understand the activities performed and information used in the assessment and treatment of geriatric hip-replacement rehabilitation, especially when it comes to discharging such patients from hospital. The interview will take no more than $\mathbf{3 0}$ minutes.

Rlght to Withdraw: You have the right to withdraw from the study at any time without penalty, and you may omit answering any specific question if you choose.

Potenttal Risk of Discomfort: There are no known potential risks of discomfort in this study.

Anonymity/Confidentdality: The data collected in this study will be treated with the utmost care and confidentiality. All data are coded such that your name will no be associated with your data. The coded raw data will only be available to the researchers involved in this study. With your permission, I would like to audio record the interview.

If you have any ethical concerns about how this study was conducted, please contact Dr. Monique Sénéchal (Chair of the Carleton University Ethics Committee for Psychological Research) monique_senechal@carleton.ca 613-520-2600, ext. 1155, If you have any other concerns about this study, please contact Dr. Thomas Garvey (Director of the School of Industrial Design), thomas_garvey@carleton.ca 613-520-5674.

l, ___ voluntarily agree to participate in the research study conducted by Diana Isaza Shelton for her masters thesis at Carleton University in the fall, 2011.

This study has received clearance by the Carleton University Psychology Research Ethics Board (\#XXX).

Participant's Signature: Date: Investigator's Signature: Date: Witness Signature: Date: 


\section{APPENDIX F \\ Informed consent form Verification Interviews}




\section{Informed Consent Form}

Study Purpose: The purpose of this study is to identify best practices and currently available decisionsupport materials for health care teams and other caregivers of post-operative hip-replacement patients in order to understand how the process underlying the decision to discharge such a patient might be improved.

Research Personnel: The following personnel are involved in this research project and may be contacted at any time: Diana Isaza Shelton (principal researcher) dibarran@connect.carleton.ca Gitte Lindgaard (Psychology Faculty Advisor) gitte lindgaard@carleton.ca 613-520-2600 ext. 2255, Professor Lois Frankel (Industrial Design Faculty Advisor) Lois Frankel@carleton.ca 613-520-5675.

Tasks and Duration: You are asked to take part in a 30-minute interview to review findings from the first round of interviews you took part in. The goal is to verify my understanding of what was said regarding the activities performed and information used in the rehabilitation process of geriatric hipreplacement patients.

Right to Withdraw: You have the right to withdraw from the study at any time without penalty, and you may omit answering any specific question if you choose.

Potential Risk of Dlscomfort: There are no known potential risks of discomfort in this study.

Anonymity/Confidentiallty: The data collected in this study will be treated with the utmost care and confidentiality. All data are coded such that your name will not be associated with your data. The coded raw data will only be available to the researchers involved in this study.

If you have any ethical concerns about how this study was conducted, please contact Dr. Monique Sénéchal (Chair of the Carleton University Ethics Committee for Psychological Research) monique senechal@carleton.ca 613-520-2600, ext. 1155, If you have any other concerns about this study, please contact Dr. Thomas Garvey (Director of the School of Industrial Design), thomas garvey@carleton.ca 613-520-5674.

I, voluntarily agree to participate in the research study conducted by Diana Isaza Shelton for her masters thesis at Carleton University in the winter 2012. This study has received clearance by the Carleton University Psychology Research Ethics Board.

Participant's Signature:

Date:

Investigator's Signature:

Date:

Withenss Signature:

Date: 


\section{APPENDIX G}

Email Instructions in preparation to Verification Interviews 
Dear [participant],

l'd like to thank you for agreeing in taking part on this interview. In preparation to our session, it will be very helpful if you can familiarize with the materials we are going to review. All you need to do is to watch a 2 min video and navigate through a diagram.

Keep in mind that the purpose of the interview is to check for accuracy of the overall process described in the two files.

The files are in a FTP secured server.

To access them, copy \& paste or type the following address in your internet browser.

You will be prompted with a login and password request, please type:

Login: geri

Password: rehab

You will see two files a video (mp4) and a document (PDF).

The video will show my interpretation of a scenario of a patient going through rehabilitation at EBH.

The PDF file:

In the first page (landscape) you will see the diagram I've created with my interpretations of the main steps and decisions the team follows from admission to discharge of the post-operative hip replacement patient.

To understand the diagram, you may find this legend helpful:

- The boxes represent the main step of the process.

- The arrows display the decisions associated with each step.

- The colours on the boxes code each profession involved. (Orange represents the steps done as a team)

- The bottom strip shows the changes in independency level.

- There is a timeline on the top.

- Clicking on each box and the bottom strip will take you to a more detailed list of information used in decision-making.

As you go through the files I expect you will have some thoughts. Keep them in mind as these will be very valuable to our discussion.

I appreciate you taking the time to revise these documents prior to our session. This will facilitate the discussion and ensure we can complete it within the allocated time.

If you encounter any issues accessing the information or have any concerns, please let me know.

Looking forward to our meeting.

Regards,

Diana 


\section{APPENDIX H}

Inquiry Interview Script 
Health care professionals with experience in geriatric rehabilitation: Hip replacement (HipR)

Introduction to the interview (the researcher will read this out aloud)

"Thank you for agreeing to take part in this interview. I am Diana Isaza Shelton the researcher for this study. The objective is to help us understand the activities performed and information used in the rehabilitation assessment and treatment of geriatric hip-replacement patients. The interview will take no more than $\mathbf{3 0}$ minutes. With your permission, I would like to audio record the interview to facilitate the data analysis."

Questions for Occupational Therapist or Physiotherapist

Patient [indlrect user]

1. Can you describe the care routine for hip replacement patients who are $65+$ ?

2. What are key success and failure factors for rehabilitation in elderly patients?

3. What are the patient's most frequent difficulties?

\section{Therapy [tasks]}

1. What activities do you do to assess a patient's hip status and progress.

2. How do you identify changes?

3. How often is the patient assessed?

\section{Data [information]}

1. What information do you rely on to decide when a hip replacement patient is ready to go home after surgery?

2. What kind of data do you use to monitor changes and their severity?

3. Are there any problems regarding [gathering, reading, organizing, sharing] data?

4. Is there anything you would like to change about the way you monitor progress? Please elaborate for me.

\section{People [interactions]}

1. What health care professionals are you often involved with in the rehabilitation process of elderly hipR patients?

2. What do you focus on?

3. How do you share data with other health care team members?

4. How do you get your patients to comply with an assigned exercise routine?

\section{Technology [tools]}

1. What kind of devices and instruments do you use to do your job?

2. Are there any forms or care material you use to record patient's data?

3. Any other technologies or tools [online, mobile, software] you use to help you in making decisions regarding the patient's treatment?

Can you think of anything else I should know about the health care decision-making process for hipR patients? 


\section{APPENDIX I}

\section{Verification Interview Script}


Thank you for being here today.

l'd like to start by gathering your thoughts about the video and the diagram that were mentioned in a prior email in preparation to this session. Did you have the opportunity to navigate through these?

\section{STEP 1}

First let's talk about the video:

1. Does it seem to reflect a common case of a patient going through geri-rehab? If not, what would be a more accurate way to describe it?

\section{STEP 2}

Now l'd like to hear you thoughts about the diagram:

2. Does it seem to reflect the main steps in the decision making process? If not, what would be a more accurate way to describe it?

3. Is there something missing, wrong or something you can add that will help me understand this better?

In the diagram, there were links to detailed information associated with each step. This was collected from forms, outcome measures and protocols gathered in the first round of interviews.(Appendix 3)

4. Does it seem to reflect what is important to you or the team in the decision making process?

5. Is there something missing, wrong or something you relevant you would like to add?

6. Please indicate in the map the points when patient interacts with the team during this process.

\section{STEP 3}

I am interested in prioritizing the information you and the team use for discharge decisionmaking, so we'll focus on this part of the model. (right side)

7. Are there minimum requirements for a patient to be discharged home?

8. If you could monitor closely, at a very detailed level, 5 specific aspects that indicate the patient's progress, what would they be?

\section{STEP 4}

Finally, I'd like to get a better understanding of the following:

9. If you notice that Rosie did not make progress for two weeks, how do you go about finding out what went wrong? Are there any steps added to this model?

10. What subtle changes not captured by the outcome measures do you use in your judgment to decide that a patient is not safe to go home? (i.e. she is at a high risk of falling)

11. What information would help you or the team reduce workload or/and increase efficiency and accuracy in the decision making process? 
125 